\title{
The role of long noncoding RNAs in hepatocellular carcinoma
}

\author{
Zhao Huang ${ }^{1 \dagger}$, Jian-Kang Zhou ${ }^{1 \dagger}$, Yong Peng ${ }^{1}$, Weifeng $\mathrm{He}^{2^{*}}$ and Canhua Huang ${ }^{1 *}$
}

\begin{abstract}
Hepatocellular carcinoma (HCC) is the most frequent subtype of primary liver cancer and one of the leading causes of cancer-related death worldwide. However, the molecular mechanisms underlying HCC pathogenesis have not been fully understood. Emerging evidences have recently suggested the crucial role of long noncoding RNAs (IncRNAs) in the tumorigenesis and progression of HCC. Various HCC-related IncRNAs have been shown to possess aberrant expression and participate in cancerous phenotypes (e.g. persistent proliferation, evading apoptosis, accelerated vessel formation and gain of invasive capability) through their binding with DNA, RNA or proteins, or encoding small peptides. Thus, a deeper understanding of IncRNA dysregulation would provide new insights into HCC pathogenesis and novel tools for the early diagnosis and treatment of HCC. In this review, we summarize the dysregulation of IncRNAs expression in HCC and their tumor suppressive or oncogenic roles during HCC tumorigenesis. Moreover, we discuss the diagnostic and therapeutic potentials of IncRNAs in HCC.
\end{abstract}

Keywords: Long noncoding RNA, Hepatocellular carcinoma, Biomarker, Targeted therapy

\section{Introduction}

Hepatocellular carcinoma (HCC) is one of the most common malignancies worldwide and ranks as the third most common cause of cancer-related death, especially in Africa and Eastern Asia due to the lack of surveillance and treatment options [1]. The risk factors underlying HCC pathogenesis are highly variable, including chronic hepatitis $B(\mathrm{HBV})$ and hepatitis $\mathrm{C}$ virus (HCV) infection, alcohol consumption, non-alcoholic fatty liver disease (NAFLD), and aflatoxin B1 intake [2]. These factors may induce DNA damage, epigenetic alterations and cancerrelated mutations, leading to the silencing of tumor suppressors (e.g. TP53, CDH1, RASSF1) and the activation of oncogenes (e.g. MYC, VEGFA, MAPK7), which eventually

\footnotetext{
*Correspondence: whe761211@hotmail.com; hcanhua@hotmail.com ${ }^{\dagger}$ Zhao Huang and Jian-Kang Zhou contributed equally to this work. ${ }^{2}$ Institute of Burn Research, Southwest Hospital; State Key Laboratory of Trauma, Burn and Combined Injury, Chongqing Key Laboratory for Disease Proteomics, Army Military Medical University, Chongqing 400038, China ${ }^{1}$ State Key Laboratory of Biotherapy and Cancer Center, West China Hospital, and West China School of Basic Medical Sciences \& Forensic Medicine, Sichuan University, and Collaborative Innovation Center for Biotherapy, Chengdu 610041, China
}

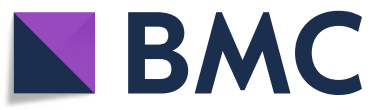

(c) The Author(s). 2020 Open Access This article is licensed under a Creative Commons Attribution 4.0 International License, which permits use, sharing, adaptation, distribution and reproduction in any medium or format, as long as you give appropriate credit to the original author(s) and the source, provide a link to the Creative Commons licence, and indicate if changes were made. The images or other third party material in this article are included in the article's Creative Commons licence, unless indicated otherwise in a credit line to the material. If material is not included in the article's Creative Commons licence and your intended use is not permitted by statutory regulation or exceeds the permitted use, you will need to obtain permission directly from the copyright holder. To view a copy of this licence, visit http://creativecommons.org/licenses/by/4.0/. The Creative Commons Public Domain Dedication waiver (http://creativecommons.org/publicdomain/zero/1.0/) applies to the data made available in this article, unless otherwise stated in a credit line to the data. contribute to HCC progression [3-6]. To date, several preventive and therapeutic strategies have been implicated in the management of HCC, as exampled by the administration of anti-hepatitis vaccine, specific kinase inhibitors (e.g. Sorafenib and Regorafenib), surgical resection and liver transplantation [7-10]. These treatments, together with biomarker screening (e.g. a-fetoprotein), have minimized HCC-related death to a certain extent, but their performance is far from acceptable therapeutic effect, thus novel diagnostic/therapeutic approaches are still urgently needed to improve the clinic outcomes of HCC.

Early HCC-related studies mainly focused on the protein-coding genes due to their central roles in the regulation of biological processes. However, less than $2 \%$ of genome DNA encodes proteins, whereas the remaining 98\% noncoding sequences and their RNA transcripts (ncRNAs) have been functionally uncharacterized and thought to be "noise" in the past [11]. Recently, increasing evidences indicate that these evolutionarily conserved ncRNAs, such as microRNA (miRNA), circular RNA (circRNA) and PIWI-interacting RNA (piRNA), particularly 
long noncoding RNA (lncRNA), play an important role in diverse physiological and pathological processes. In 1990, the first IncRNA H19, which restricts organ growth via decreasing IGF2 expression, was identified in fetal liver tissue $[12,13]$. Next year, the lncRNA XIST mediating X chromosome inactivation was found [14]. To date, over 50, 000 genes have been found to transcribe lncRNAs and their number is still rapidly growing [15]. These lncRNAs are differentially expressed in different tissues and cancers, including HCC [16]. Currently, the roles of most lncRNAs in HCC remain elusive, while a small part of which has been extensively investigated. For instance, lncRNA HULC is upregulated in HCC and has been shown to promote HCC growth, metastasis and drug resistance [17-19]. Intriguingly, some HCC-related lncRNAs are present in body fluids, which are easy to detect and analyze, making them have the potential to be attractive biomarkers in liquid biopsy of HCC. For instance, lncRNA-WRAP53 in serum is an independent prognostic marker to predict high relapse rate of HCC patients [20]. These vital roles and unique properties of lncRNAs suggest their potential clinical value in the HCC diagnosis and treatment. In this review, we briefly introduce dysregulation of IncRNAs expression in HCC, and summarize how lncRNAs regulate HCC progression by acting as tumor suppressor or oncogene. In addition, we discuss the diagnostic and therapeutic potential of lncRNAs in HCC.

\section{LncRNA as a modulator of liver microenvironment and chronic liver diseases}

Liver cancer is distinguished from other cancer types by several unique features, including viral infection, regenerative signals and hypoxic microenvironment. These factors provide both opportunities and challenges for HCC cell proliferation and survival. Importantly, lncRNA modulates immune response, liver regeneration and redox signaling, which play critical roles in the regulation of liver microenvironment and chronic liver diseases. Dysregulation of lncRNA in these processes leads to chronic hepatitis, liver outgrowth and oxidative stress, which eventually result in the initiation and progression of HCC (Fig. 1).

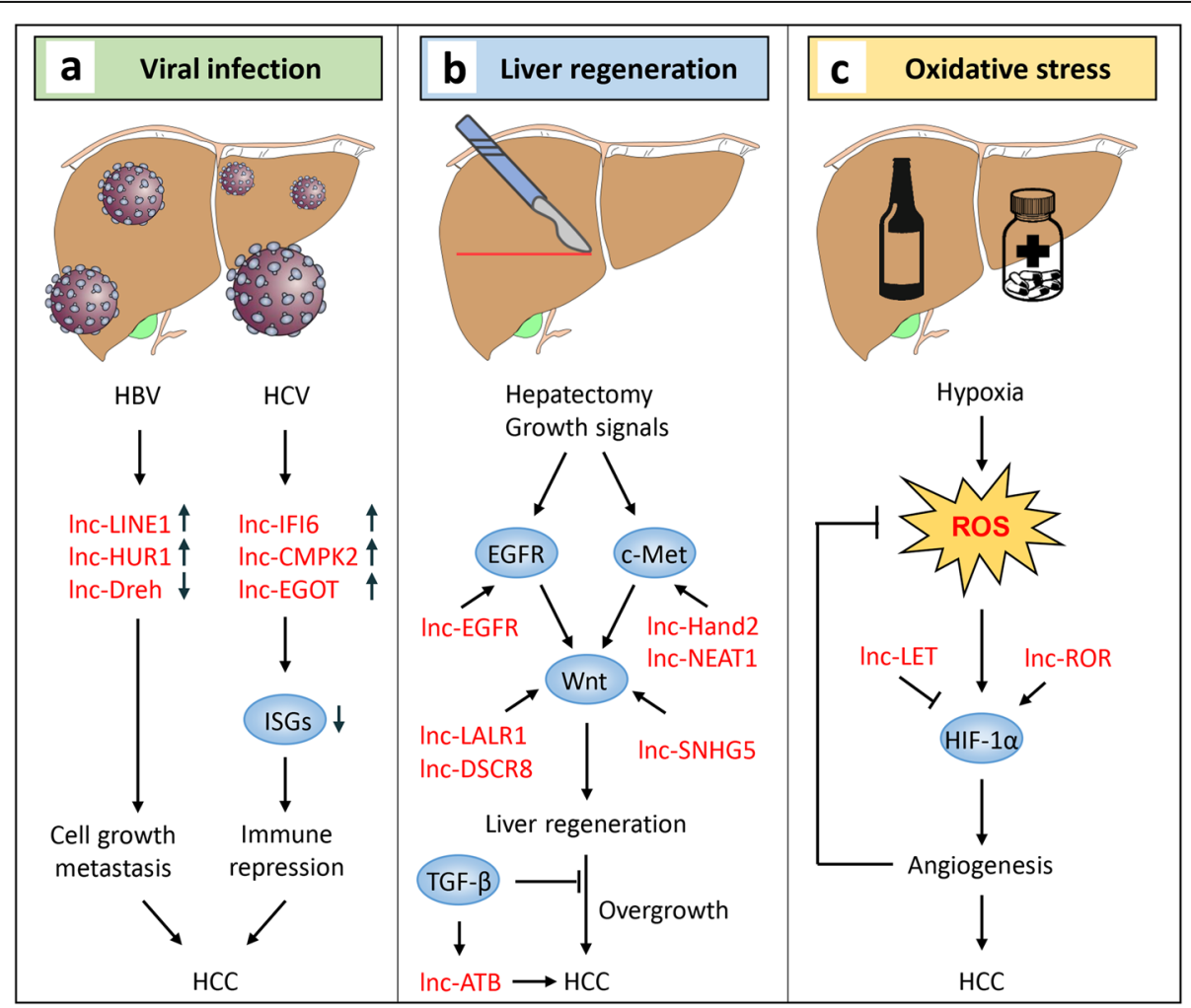

Fig. 1 LncRNAs modulate liver microenvironment and chronic liver diseases. LncRNAs are involved in physiological and pathological processes, including (a) Viral infection and immune repression. Virus-induced IncRNAs are capable of promoting cell proliferation or suppressing host immune response, resulting in chronic infection and HCC formation. $\mathbf{b}$ Liver regeneration and outgrowth. In response to hepatectomy, liver is regenerated via activating proliferative signalings. These signalings can also be stimulated by certain IncRNAs independent of tissue loss, leading to liver overgrowth and HCC. $\mathbf{c}$ Hypoxic liver injury and oxidative stress. Drug detoxification induces ROS accumulation in liver, which upregulates HIF-1a to facilitate blood vessel formation therefore relief oxidative stress. To some similarities, several IncRNAs also activate HIF-1a to support HCC survival under hypoxic condition. ISGs, IFN-stimulated genes. ROS, reactive oxygen species 


\section{Viral infection}

Hepatitis $\mathrm{B}$ virus (HBV) and hepatitis $\mathrm{C}$ virus (HCV) are two major viruses invading liver and causing chronic inflammation. More than 240 and 70 million people are infected respectively with $\mathrm{HBV}$ and $\mathrm{HCV}$ worldwide, a part of who tend to develop HCC if untreated [21, 22]. Hepatitis viruses hijack host cells to facilitate their replication or production via multiple mechanisms, one of which is regulating the transcription of certain lncRNAs. For instance, the HBV $\mathrm{X}$ protein $(\mathrm{HBx})$ upregulates oncogenic lncRNA HUR1, which binds and blocks p53 to promote HCC growth [23]. Besides, HBx can also downregulate tumor suppressive lncRNA Dreh, leading to re-expression of vimentin and promoting HCC metastasis [24]. During infection, the host immune is activated to restrict viral replication. However, the invaded hepatitis viruses are able to alter Toll-like receptor (TLR) signaling, resulting in a defective immune response that is inadequate for virus clearance. It allows the virus to escape from immune surveillance, in which lncRNAs play crucial roles. It has been shown that infection of $\mathrm{HCV}$ upregulates the level of a series of lncRNAs such as IFI6, CMPK2 and EGOT that inhibit the expression of IFN-stimulated genes (ISGs), leading to immune suppression and chronic inflammation [25-27]. These findings indicate that viruses modulate antiviral response through lncRNAs encoded by host or itself genome. Intriguingly, lncRNA can also be generated from an integrated genome. Lau et al. reported a viral-human gene fusion that produces a chimeric lncRNA HBx-LINE1, which promotes HCC through activating Wnt signaling [28]. This chimeric IncRNA can be detected in 23.3\% HBV bearing HCC samples and decrease the survival of HCC patients, suggesting $\mathrm{HBV} / \mathrm{HCV}$ associated lncRNAs might be potential biomarkers in $\mathrm{HCC}$ risk evaluation and diagnosis.

\section{Liver regeneration}

Liver is the only visceral organ capable of regeneration after partial hepatectomy or chemical injury. After a hepatectomy, hepatic growth factor (HGF) is released due to elevated urokinase activity, which potently activates EGFR and c-Met $[29,30]$. EGFR and c-Met promote hepatocyte proliferation through activating multiple signalings, such as Wnt $[31,32]$. Once regeneration is completed, TGF- $\beta$ represses the function of urokinase and HGF thus brings liver cells back to the quiescent state [33]. Several lncRNAs are involved in this process. For example, lncRNA-LALR1 has been found to suppress Axin1 thus activating Wnt signaling, which stimulates hepatocyte proliferation during liver regeneration [34]. Besides, lncHand2 is capable of upregulating the expression of Nkx1-2, thereby activating c-Met in hepatocyte to facilitate liver regeneration [35]. However, persistent proliferative signaling induced by IncRNA dysregulation frequently leads to liver tumorigenesis. For instance, lncRNA DSCR8 [36] and SNHG5 [37] have been shown to upregulate Wnt and result in liver tumor growth, whereas lnc-EGFR [38] and IncRNA NEAT1 [39] are capable of activating EGFR and c-Met respectively, leading to HCC development. These lncRNAs are probably activated in the absence of liver tissue loss or failed to be silenced by quiescent signal TGF- $\beta$. Indeed, TGF- $\beta$ may upregulate certain lncRNAs such as ATB to promote HCC metastasis [40], and the key regulatory mechanisms to determine whether an oncogenic or tumor suppressive role of TGF- $\beta$ in this context remains unclear.

\section{Oxidative stress}

Liver accounts for approximately $2 \%$ of body weight but receives about $25 \%$ of cardiac output. Sufficient blood supply is indispensable for its oxygen demand, whereas poor oxygen delivery or inadequate antioxidant machinery frequently results in hypoxic liver injury, an oxidative stress-associated liver disease [41]. In addition, various risk factors such as alcohol consumption, viral infection, drug detoxification and metabolism also markedly induce accumulation of reactive oxygen species (ROS), leading to oxidative stress in liver. To adapt to this hypoxic microenvironment, HCC cells develop survival strategies such as promoting angiogenesis, thereby receiving additional oxygen supply from the bloodstream [42]. This process involves HIF- $1 \alpha$, a master transcription factor that facilitates angiogenesis. Recent studies revealed that several IncRNAs are sensitive to hypoxia and might function through HIF-1 $\alpha$. One of hypoxiaresponsive lncRNAs is linc-RoR, which is induced by oxidative stress and upregulates HIF- $1 \alpha$ to support HCC cell survival [43]. In contrast, IncRNAs that negatively regulate HIF-1 $\alpha$, including lncRNA LET, are downregulated during HCC progression [44]. Mechanistically, lncRNA-LET interacts with a RNA-binding protein NF90 and promotes its degradation, leading to destabilization of HIF- $1 \alpha$ mRNA. In response to hypoxia, HDAC3 is induced and represses the transcription of IncRNA-LET, resulting in expression of HIF- $1 \alpha$ and HCC metastasis [44]. For protecting liver from oxidative damage, natural antioxidant supplies including green tea, jujube honey and virgin olive oil are encouraged [45], but the roles of lncRNAs in this process is yet to be determined.

\section{Aberrant expression of IncRNA in HCC}

The biogenesis of lncRNAs shows high similarities with that of protein-coding transcripts. Epigenetic modification, transcription complex recruitment and RNA processing are major events regulating lncRNA biogenesis. Before transcription, active chromatin marks are commonly present within lncRNA promoter, including the acetylation of $\mathrm{H} 3 \mathrm{~K} 9$ and $\mathrm{H} 3 \mathrm{~K} 27$, as well as the dimethylation or trimethylation of H3K4 [46]. In contrast, the 
trimethylation of H3K27 is recognized as a repressive chromatin mark. For example, knockdown of EZH2, a methyltransferase responsible for H3K27me3 modification, has been shown to reactivate the transcription of lncRNAs in embryonic stem cells [47]. These evidences indicate that the epigenetic modification of lncRNA genes may follow nearly the same regulatory rules as proteincoding genes. Interestingly, another transcriptional repression mark $\mathrm{H} 3 \mathrm{~K} 9 \mathrm{me} 3$ is more enriched in the promoter region of lncRNAs compared with mRNAs, suggesting some unique features of lncRNAs in their histone modification patterns [48]. The detailed mechanisms underlying these epigenetic modifications remain elusive, whereas some chromatin remodeling complex such as Isw2, Swr1, Ino80 and Rsc are probably involved [49].

Next, in the presence of active chromatin marks or the absence of repressive marks, RNA polymerase II is recruited to initiate the transcription of lncRNAs, sometimes in a bidirectional way to yield divergent transcripts. Generally, lncRNA genes tend to share the same promoter with their neighbor protein-coding genes [50]. Besides, some other transcription patterns have been extensively reviewed elsewhere [51]. Then, the majority of nascent transcripts are processed into mature lncRNAs through canonical ways like mRNAs, including methylguanosine capping at $5^{\prime}$ end, polyadenylation to form a poly-A tail at $3^{\prime}$ end, and splicing to remove introns. Alternatively, some lncRNAs have been shown to undergo non-canonical processing ways. For instance, the lncRNA MALAT1 and MEN $\beta$ are cleaved by tRNA processing enzymes RNase $\mathrm{P}$ and RNase $\mathrm{Z}$ to form triple-helical structures at their $3^{\prime}$ end, which protects them from degradation and facilitates their cellular accumulation in the absence of poly(A) tail $[52,53]$. In summary, the biogenesis of lncRNA and mRNA is broadly similar, but considerable differences exist and endow these RNA molecules with unique features and functions.

Aberrant lncRNA biogenesis has been implicated in the pathogenesis of various diseases, including HCC. Indeed, high-throughput platforms such as RNA-sequencing and microarray have revealed distinct lncRNA expression profiles in HCC tissues compared with noncancerous liver tissues (Table 1), suggesting that biogenesis of certain

Table 1 Some dysregulated LncRNAs and their roles in the progression of HCC

\begin{tabular}{|c|c|c|c|c|c|}
\hline LncRNAs & Roles in HCC & Binding partners & Action modes & Outcomes & Refs \\
\hline Dreh & Tumor suppressor & Vimentin protein & Cytoskeleton reorganization & $\begin{array}{l}\downarrow \text { metastasis } \\
\downarrow \text { proliferation }\end{array}$ & [24] \\
\hline ATB & Oncogene & miR-200 & miRNA sponge & $\uparrow$ metastasis & {$[40]$} \\
\hline UFC1 & Oncogene & $\begin{array}{l}\beta \text {-catenin mRNA } \\
\text { HuR protein }\end{array}$ & mRNA stabilization & $\uparrow$ proliferation & [54] \\
\hline PXN-AS1 & Oncogene & PXN mRNA & mRNA stabilization & $\uparrow$ proliferation & {$[55]$} \\
\hline ANRIL & Oncogene & $\begin{array}{l}\text { EZH2 protein } \\
\text { Target gene DNA }\end{array}$ & Transcriptional suppression & $\uparrow$ proliferation & {$[56]$} \\
\hline TUG1 & Oncogene & $\begin{array}{l}\text { EZH2 protein } \\
\text { Target gene DNA }\end{array}$ & Transcriptional suppression & $\begin{array}{l}\uparrow \text { proliferation } \\
\uparrow \text { glycolysis }\end{array}$ & {$[57,58]$} \\
\hline Inc- $\beta$-Catm & Oncogene & $\begin{array}{l}\text { EZH2 protein } \\
\beta \text {-catenin protein }\end{array}$ & Protein stabilization & $\uparrow$ stemness & [59] \\
\hline GIHCG & Oncogene & $\begin{array}{l}\text { EZH2 protein } \\
\text { Target gene DNA }\end{array}$ & Transcriptional suppression & $\begin{array}{l}\uparrow \text { proliferation } \\
\uparrow \text { metastasis }\end{array}$ & {$[60]$} \\
\hline DANCR & Oncogene & $\beta$-catenin mRNA & mRNA stabilization & $\uparrow$ stemness & [61] \\
\hline MALAT1 & Oncogene & miR-143-3p & miRNA sponge & $\begin{array}{l}\uparrow \text { metastasis } \\
\uparrow \text { proliferation }\end{array}$ & [62] \\
\hline HULC & Oncogene & $\begin{array}{l}\text { miR-186 } \\
\text { miR-9 }\end{array}$ & miRNA sponge & $\begin{array}{l}\uparrow \text { proliferation } \\
\uparrow \text { lipogenesis }\end{array}$ & {$[63,64]$} \\
\hline XIST & Tumor suppressor & miR-92b & miRNA sponge & $\begin{array}{l}\downarrow \text { metastasis } \\
\downarrow \text { proliferation }\end{array}$ & [65] \\
\hline PVT1 & Oncogene & NOP2 protein & Protein stabilization & $\uparrow$ stemness & [66] \\
\hline HOTTIP & Oncogene & $\begin{array}{l}\text { miR-192 } \\
\text { miR-204 }\end{array}$ & miRNA sponge & $\uparrow$ glutaminolysis & {$[67]$} \\
\hline DILC & Tumor suppressor & IL-6 DNA & Transcriptional suppression & $\downarrow$ stemness & [68] \\
\hline ICR & Oncogene & ICAM-1 mRNA & mRNA stabilization & $\uparrow$ stemness & {$[69]$} \\
\hline ZFAS1 & Oncogene & miR-150 & miRNA sponge & $\uparrow$ metastasis & [70] \\
\hline $\mathrm{MVIH}$ & Oncogene & PGK1 protein & Protein localization & $\uparrow$ metastasis & [71] \\
\hline CASC9 & Oncogene & HNRNPL protein & Protein phosphorylation & $\uparrow$ proliferation & {$[72]$} \\
\hline
\end{tabular}


lncRNAs is dysregulated during HCC development [54, 73]. These aberrant biogenesis events basically include the epigenetic silence/activation of tumor-suppressive/promoting lncRNAs, the transcriptional activation/repression of lncRNAs by certain oncogenic/tumorsuppressive transcription factors, the special processing patterns that endow lncRNAs with oncogenic functions, and the binding of IncRNAs with microRNA or proteins that affect lncRNA stability (Fig. 2).

\section{Epigenetic modification}

During HCC progression, abnormal chromatin marks including DNA methylation and histone modification at lncRNA genes are universally identified [74], leading to the decrease of HCC-repressive lncRNAs (Fig. 2a) or increase of HCC-promoting lncRNAs (Fig. 2b). For instance, DNA methyltransferases DNMT1 and DNMT3 induce hypermethylation at the promoter of tumor-suppressive lncRNA MEG3, whose epigenetic silence results in apoptosis resistance of HCC cells and liver tumor growth [75]. In contrast, some HCC-promoting lncRNAs are induced by activated epigenetic marks. Tang et al reported that the upregulation of linc00441 expression was due to enhanced H3K27 acetylation [76]. Overexpressed linc00441 in turn recruits DNMT3A to methylate and inactivate its neighbor gene RB1, thereby promoting the proliferation of HCC cells [76].

\section{Transcriptional activation}

It has been well established that a series of oncogenic transcriptional factors/co-factors are overexpressed in HCC, including YAP, c-Myc and $\beta$-catenin. These transcriptional factors initiate the transcription of not only protein-coding genes but also non-coding genes such as lncRNAs. For example, a systemic study revealed that the transcription of numerous lncRNAs is regulated by the transcription factor Myc [77] (Fig. 2c). Given that enhanced Myc signaling in HCC, a class of lncRNAs should be at least partially responsible for Myc-driven HCC progression. Indeed, it has been reported that IncRNA linc00176, which overexpresses exclusively in HCC, is transcribed by Myc. Depletion of this Myc-regulated lncRNA led to cell cycle arrest and necroptosis in HCC cells, suggesting that lncRNA transcription contributes largely to the oncogenic function of HCC relevant oncoproteins [78].

\section{RNA processing}

Certain primary lncRNA transcripts undergo special processing, such as exon inclusion (Fig. 2d). These processing modes might provide oncogenic function for HCC development. A splicing factor MBNL3, which is overexpressed in fetal liver and HCC tissue but loss in adult normal liver, has been shown to induce exon 4 inclusion of lncRNA PXN-AS1. This alternative splicing event allows lncRNA PXN-AS1 to interact with the PXN mRNA and protects it from degradation, leading to its overexpression and consequent HCC development [55].

\section{MiRNA sponging}

Several lncRNAs function as competitive endogenous RNA (ceRNA) to bind miRNAs therefore also known as

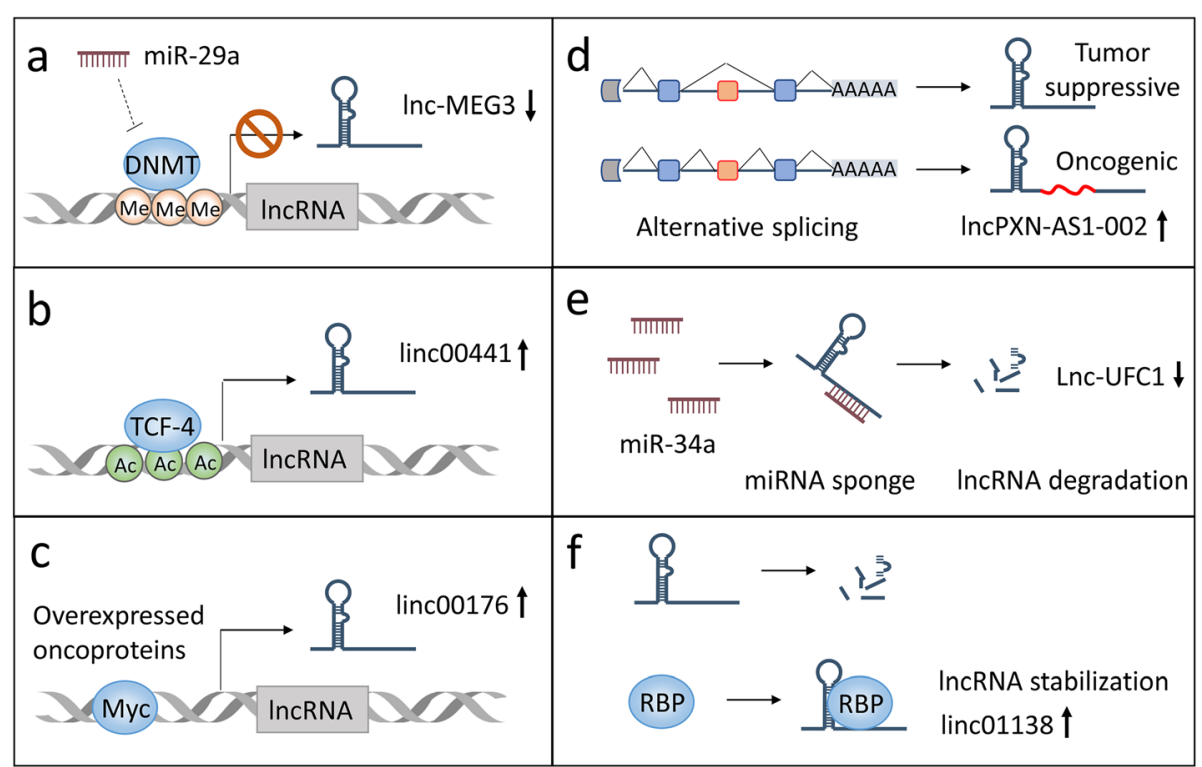

Fig. 2 Abnormal expression of IncRNA in HCC. a Epigenetic silencing of HCC-suppressive IncRNAs; b Epigenetic activation of HCC-promoting IncRNAs; c Transcriptional activation by HCC-related oncoproteins; d RNA processing that endows IncRNA with HCC-promoting properties; e Loss of tumor-suppressive miRNAs leads to re-expression of targeted oncogenic IncRNAs; f RBP-induced stabilization of HCC-promoting IncRNAs. RBP, RNA-binding protein 
miRNA sponge. This lncRNA-miRNA association leads to the re-expression of miRNA target genes, which will be discussed in the next section. Not surprisingly, sponging of miRNAs affects the expression of lncRNA itself, providing another layer of post-transcriptional regulation of lncRNAs (Fig. 2e). It has been shown that miR-34a directly binds lncRNA-UFC1 to decrease its half-life, thereby suppressing HCC cell proliferation induced by IncRNA-UFC1 [54]. Given that miRNAs are globally downregulated during HCC development, more oncogenic IncRNAs are expected to be reactivated thus form an aberrant lncRNA expression profile.

\section{Protein binding}

Besides miRNAs, some kinds of proteins can also bind lncRNAs to regulate their turnover. These proteins mainly include RNA-binding proteins (RBPs), which are conventionally known as binding mRNA. In terms of considerable similarities existed between lncRNAs and mRNAs, many RBPs have been found to regulate IncRNA stability through physical interaction (Fig. 2f). Among these RBPs, insulin like growth factor-2 mRNA-binding proteins $1 / 3$ (IGF2BP1/3) binds and stabilizes linc01138 on its 2201560-nt fragment, which is required for the growth and metastasis of HCC cells [79]. Moreover, the aforementioned lncRNA UFC1 is able to interact with another RBP termed human antigen R (HuR) through its 1102-1613-nt fragment, which is indispensable for the HCC-promoting function of IncRNA-UFC1 [54]. These evidences suggest that abnormal lncRNA biogenesis in HCC can be attributed to RBP-regulated IncRNA decay.

\section{Functional mechanisms of IncRNA in HCC}

LncRNAs exert their functions to regulate cell fate through multiple ways, including DNA binding, RNA interaction, associating with proteins, and producing small peptides. Firstly, binding to DNA allows lncRNAs to remodel chromatin structure and epigenetic modifications, thus regulating the expression of target genes. Secondly, lncRNAs interact with mRNAs or miRNAs as molecular sponge, thereby modulating the stability and translation of mRNAs or the binding of miRNAs with their own targets. Thirdly, lncRNAs are capable of binding with proteins to regulate their conformation, localization or stability, the formation or disassociation of protein complex as well as other aspects of functions. In addition, a part of IncRNAs contain small open reading frames (sORFs) that encode peptides with biological functions. Compelling evidences suggest that IncRNAs participate in HCC progression through regulation of their binding partners and peptidecoding properties (Fig. 3).

\section{DNA binding and chromatin remodeling}

Nuclear lncRNAs are widely observed to be associated with DNA, including protein-coding or non-coding regions (Fig. 3a). This RNA-DNA binding allows lncRNAs to regulate genes in cis (lncRNA genes and target genes are localized at the same chromosome) or in trans (different chromosomes). A well-characterized lncRNA that binds DNA is XIST, which mediates X chromosome inactivation during the early developmental process [14]. At present, a growing number of lncRNAs have been shown to bind with DNA, however, only a small fraction has been functionally annotated. For instance, a high-throughput study identified 276 lncRNAs interacting with DNA, among which lncRNA MEG3 was further validated to be capable of regulating the TGF- $\beta$ pathway through interacting with DNA [80]. The typical lncRNA-DNA interaction site may lie in the promoters or other regulatory DNA sequences (such as enhancers) of certain genes, thereby regulating gene expression. For example, lncRNA TUG1 binds with the promoter region of PGC- $1 \alpha$ gene, enhancing the promoter activity and resulting in PGC- $1 \alpha$ overexpression [81]. Mechanistically, this transcriptional control by lncRNA-DNA interaction is usually achieved through the formation of RNA-DNA hybrid (also known as R loop) to alter chromatin structure [82]. These changed chromatin structure may provide signals to recruit biomolecules (such as epigenetic modifiers) to modulate gene expression, or spatially bring promoters and enhancers/repressors together to regulate the transcriptional activities. It has been reported that IncRNA-DNA hybrid has been found to accelerate transcriptional induction, which is implicated in the fast adaptation of organisms to environmental stimuli [83]. Another report has shown that IncRNA Khps1 directly interacts with the promoter of SPHK1 gene to form a lncRNA-DNA structure, where it recruits histone acetyltransferase p300/CBP to activate SPHK1 expression [84].

HCC can be in part attributed to particular lncRNADNA interaction. Abnormal chromatin marks are frequently observed during $\mathrm{HCC}$ development largely due to dysregulation of epigenetic modifiers, including DNMTs, EZH2, HDACs, PCAF, and other effectors that regulate these epigenetic modifying enzymes [85-87]. Importantly, accumulating evidences have suggested that some of these epigenetic modifiers can be regulated by lncRNAs in HCC, leading to aberrant epigenetic changes such as hypomethylation, hypermethylation and other modifications [74]. For instance, UHRF1 drives HCC through inducing global DNA hypomethylation, and further study revealed that lncRNA UPAT can directly bind to UHRF1 and therefore protect it from degradation, indicating that lncRNA UPAT-mediated UHRF1 stabilization may be an oncogenic factor of HCC $[88,89]$. Besides, hypermethylation of certain genes are also involved in HCC progression. That 


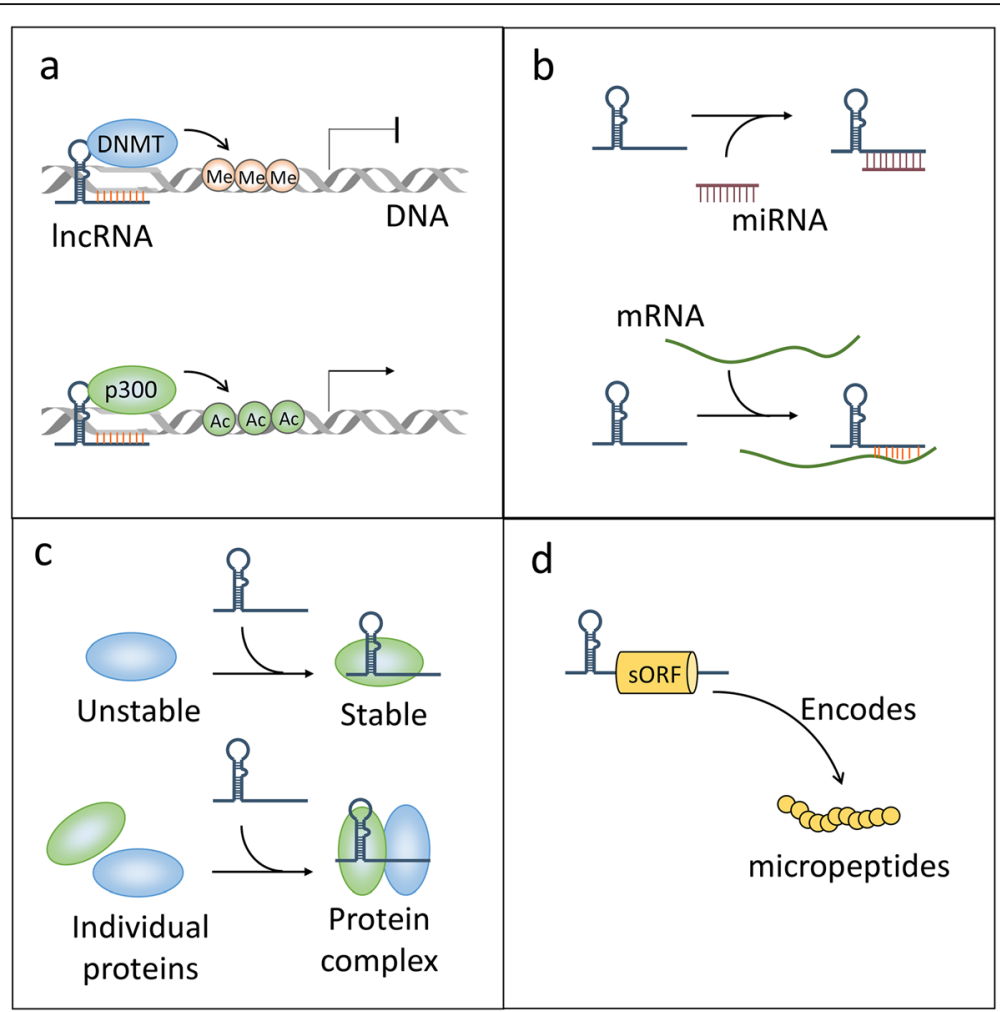

Fig. 3 Functional mechanisms of IncRNA in HCC. a LncRNAs interacts with DNA to regulate gene expression through binding with promoters or distal regulatory elements, where they recruit epigenetic modifiers to promote or repress gene expression. $\mathbf{b}$ LncRNAs bind to mRNAs to regulate their stability, thereby regulating gene expression. Besides, IncRNAs can also bind to miRNAs as molecular sponge, leading to the reactivation of genes targeted by miRNAs. c LnCRNAs interact with proteins to regulate their stability or facilitate the formation of protein complex when they function as scaffold. $\mathbf{d}$ Several IncRNAs hold the potential to encode small peptide, through which exhibit their biological functions

situation includes the two lncRNAs ANRIL and TUG1, which are both able to recruit EZH2 to induce H3K27me3 modification at the promoter region of KLF2, thus repressing its transcription and inhibiting HCC cell growth [56, 57]. Interestingly, many other lncRNAs, such as HOTAIR, lnc- $\beta$-Catm, GIHCG and UCA1, have been also shown to be capable of recruiting EZH2 to play certain roles in the progression of HCC, suggesting an extensive connection between EZH2 and lncRNAs [59, 60, 90, 91]. Given that epigenetic modification is a reversible process that differs from gene mutation, targeting lncRNA-mediated epigenetic regulation might be a promising strategy for HCC treatment.

\section{Sponging mRNAs and miRNAs}

RNR-RNA interaction represents a crucial mechanism to regulate cellular events through complementary basepairing. It has been extensively investigated that miRNAs bind mRNAs to regulate mRNA turnover, thus affecting gene expression [92]. LncRNAs are capable of interacting with both mRNAs and miRNAs, making RNA regulation more comprehensive (Fig. 3b). Generally, IncRNA-mRNA interaction regulates the stability and localization of bound
mRNAs, whereas IncRNA-miRNA interaction represses the binding of miRNAs with their own targets, namely miRNA sponge (also known as competitive endogenous RNA, ceRNA). For instance, a genome-scale RNA interactome study has shown a critical role of lncRNA TINCR in somatic tissue differentiation through interacting with a variety of differentiation-related mRNAs. Mechanistically, TINCR binds to those mRNAs harboring a 25-nt TINCR box motif, and then the STAU1 protein is recruited to interact with the TINCR-mRNA complex, therefore stabilizing the bound mRNAs and promoting their expression [93]. Another lncRNA MALAT1 has been shown to interact with nascent pre-mRNAs, thus localizing to active chromatin sites, which may facilitate the processing of premRNAs [94]. Besides the regulation of mRNA stability and translocation, lncRNAs frequently function as molecular sponge to regulate numerous miRNAs through direct binding. Similar to mRNA binding, those lncRNAs associating with miRNAs usually contain specific binding region. One such example is lncRNA H19, which contains two functional binding sites of let-7 miRNA. Such binding releases let-7 from and activates the expression of its targets, Dicer and Hmga2 [95]. Another study using miR-CLIP 
approach identified $\mathrm{H} 19$ functions as miR-106a sponge and such interaction plays vital roles in the differentiation of skeletal muscle cells [96]. Interestingly, lncRNA-miRNA interaction sometimes affects cellular processes by modifying the function of IncRNA itself, but not the bound miRNA. For instance, LINC00673 acts as a tumor suppressor by inhibiting SRC-ERK signaling, whereas a $G$ to A nucleotide mutation on it creates a binding site for miR1231, which represses the antitumor function of LINC00673 [97].

The crosslink between lncRNAs and other RNA molecules (mRNAs and miRNAs) is an emerging issue related to HCC progression. Certain lncRNAs, such as UFC1, can stabilize $\beta$-catenin mRNA through binding with the mRNA stabilizing protein $\mathrm{HuR}$, leading to the activation of Wnt signaling and consequent HCC progression [54]. Another lncRNA DANCR stabilizes the mRNA of $\beta$ catenin via direct binding, thus promoting HCC [61]. More generally, however, IncRNAs indirectly affect the stability of mRNAs through regulation of miRNAs, but not the direct IncRNA-mRNA binding. Indeed, miRNAs have been shown to globally downregulated during HCC development, which can be at least partially attributed to defects in miRNA processing machinery, the impaired pre-miRNA nuclear export, and the IncRNA-mediated miRNA dysregulation [98-100]. There are two major mechanisms underlying miRNA regulation by lncRNAs, namely epigenetic modification and physical association (miRNA sponge). Epigenetic regulation of miRNAs by lncRNAs including HOTAIR and GIHCG has been discussed above, and some epigenetic modifiers such as EZH2 are required for this process. In contrast, a large number of lncRNAs including MALAT1, FTX and MUF can directly bind to miRNAs to regulate their function $[62,101,102]$. These miRNA sponges interrupt the association between miRNAs and their target mRNAs to result in the reactivation of certain HCC-related genes. One of such cases is the well-known lncRNA HULC, which acts as a competing endogenous RNA for miR186, thereby upregulating HMGA2 to support HCC growth [63]. Alternatively, some miRNA sponge such as lncRNA XIST functions as a tumor suppressor via interacting with miR-92b, which represses the proliferation and metastasis of HCC [65]. It is worth noted that a single lncRNA might bind a variety of RNA species simultaneously, suggesting the binding of lncRNAs with other RNA species can be effective and multi-functional.

\section{Protein interaction and regulation}

The association of lncRNAs with proteins orchestrates protein localization or stability, as well as protein complex assembly or sequestration of proteins from their own binding partners, thereby executing their biological function (Fig. 3c). For instance, lncRNA XIST plays a central role in the $\mathrm{X}$ chromosome inactivation, and this function is closely related to the control of protein localization. Chen et al. recently reported that XIST binds with the LBR thereby directing the inactivated $\mathrm{X}$ chromosome to localize at the nuclear lamina, where XIST can spread across the $\mathrm{X}$ chromosome to silence transcription [103]. Besides, various lncRNAs, such as FAL1, AB074169 and MALAT1, have been shown to regulate the stability of bound proteins including BMI1, KHSRP and SREBP-1c, respectively [104-106]. This may be due to an altered binding affinity between protein turnover machinery and lncRNA-bound proteins. In addition to regulating protein localization and stability, lncRNAs can also mediate assembly of protein-protein complex via function as a scaffold. For example, two ends of IncRNA HOTAIR bind respectively with $\mathrm{PRC} 2$ and $\mathrm{LSD} 1$, thus tether these two distinct histone modifiers together to form a new protein complex [107]. Moreover, a recent study reported that lncKdm2b interacts with SRCAP protein to facilitate the assembly of SRCAP remodeling complex, promoting the renewal of embryonic stem cells [108]. In contrast, some lncRNAs act as competitive binding partners to sequester proteins from their original substrates, leading to the disassociation of protein complex. Such lncRNAs include Mhrt, which competitively interacts with the helicase domain of Brg1, leading to the disassociation of Brg1 and its genomic DNA targets thereby repressing Brg1-induced chromatin remodeling [109]. Similarly, IncRNA NORAD has been shown to sequester PUMILIO proteins from mRNAs, which is implicated in the maintenance of genomic stability [110].

Numerous studies have indicated that IncRNA-protein interaction play key roles in the pathogenesis of HCC through distinct mechanisms, including regulation of protein localization and stability, as well as complex assembly and protein sequestration. 1) The subcellular localization of many HCC-related proteins has been reported to be regulated by lncRNAs. For instance, lncRNA MUF interacts with AXNA2 to promote its cytoplasmic translocation, where AXNA2 activates WNT signaling thus leading to HCC progression [102]. 2) LncRNA-mediated stabilization of oncoproteins and tumor suppressors can result in the progression and suppression of HCC, respectively. One of such oncoprotein NOP2 can be bound and stabilized by IncRNA PVT1, therefore promoting the proliferation of HCC cells [66]. In contrast, the well-known tumor suppressor p53 is ubiquitinated and degraded by MDM2, which has been fully documented. LncRNA PRAL facilitates the interaction of p53 with HSP90 thus preventing the binding of p53 with MDM2, leading to the stabilization of p53 and the suppression of HCC growth [73]. Similarly, lncRNA PSTAR physically binds to hnRNP $K$ protein and enhances its SUMOylation, which facilitates the formation of the p53-hnRNP $\mathrm{K}$ protein complex, thereby competitively 
blocking MDM2-dependent p53 protein degradation and inhibiting HCC cell proliferation [111]. 3) LncRNAs HOTAIR is capable of serving as a scaffold to bind with PRC2 and E3 ligase Mex3b simultaneously, facilitating the degradation of PRC2 and promoting HBV-induced HCC progression [112]. 4) LncRNAs can also sequester proteins from their substrates to play some roles in HCC. For example, DNA replication licensing factor MCM2 promotes DNA replication and is related to $\mathrm{HCC}$ cell division. LncRNA FTX binds with MCM2 thereby sequestering it from chromatin, leading to cell cycle arrest and inhibition of HCC growth [101]. Unlike interacting with RNA species via base-pairing, lncRNAs bind proteins mainly through their complex secondary structure. Though several tools have been developed to predict the structure of IncRNAs [113], the mechanism underlying lncRNA-protein interaction is yet to be elucidated due to lack of in-depth researches.

\section{Encoding small peptides}

LncRNAs are defined as a kind of long transcripts that do not encode proteins. However, recent studies revealed that some lncRNAs indeed contain small open reading frames (sORFs, less than 100 amino acids) producing functional peptides (Fig. 3d). As early as 2002, a plant-derived lncRNA ENOD40 was found to encode two small peptides (12 and $24 \mathrm{aa)}$ that interact with sucrose synthase [114]. Following study indicated that the 12-aa peptide binds sucrose synthase through disulfide bond, elevating the sucrose cleavage activity of sucrose synthase [115]. With the development of bioinformatic and sequencing technologies in recent years, more sORFs have been identified in transcripts that previously annotated as non-coding. For instance, ribosome profiling and Poly-Ribo-Seq are able to screen ribosome-associated RNAs, many of which are lncRNAs thus suggest their coding potential [116, 117]. Further analysis revealed that $40 \%$ of human lncRNAs might be translated, especially those located in the cytoplasm [118]. However, it is worth noted that binding to ribosome does not mean that they are truly translated. To validate the production of peptides, a mass spectrometrybased approach has been applied to confirm that only a small subset of lncRNAs are translated, which may be due to the rapid degradation of small peptides [119].

To date, very few efforts have been devoted to elucidating the functions of IncRNA-encoded small peptides in HCC development. Recently, a relevant study using the ribosome profiling method revealed that a 99-aa peptide termed KRASIM, which is encoded by lncRNA NCBP2AS2, binds KRAS protein to inhibit ERK signaling, leading to the suppression of HCC cell growth [120]. The lack of relevant study might be attributed to multiple reasons. Firstly, the small peptides are probably unstable therefore not easy to detect. Secondly, a fraction of these small peptides are not homolog to well-annotated proteins, making it difficult to predict their function. It is also possible that a subset of micropeptides actually have no biological function. Therefore, further investigations are required to better characterize the roles of IncRNAencoded peptides in HCC.

\section{Significance of IncRNA in HCC hallmarks}

Similar hallmarks are shared by different cancer types, including persistent proliferation, resistant to cell death, and elevated invasive capability [121]. HCC-related lncRNAs promote or suppress these cancerous phenotypes through the interplay with their binding partners, underlying rational therapeutic strategies for the treatment of HCC (Fig. 4).

\section{Sustaining proliferative signaling}

Cell proliferation is basically triggered by receptor tyrosine kinases (RTKs) activation and cell cycle progression. Normal cells restrict their proliferation to maintain a proper architecture of organisms, while constitutive activation of RTKs or bypass of cell cycle checkpoints can lead to tumorigenesis, including HCC. On one hand, hyperactivation of RTKs such as EGFR, c-Met, IGF1R and IGF2R, have been reported to play important roles in supporting HCC growth $[122,123]$. This may largely due to constitutive activation of their downstream signaling including PI3K/Akt and Ras/Raf/MEK/ERK pathways, resulting in a high proliferation rate of HCC cells. On the other hand, the progression of cell cycle is also required for cell proliferation. Generally, cell cycle is precisely regulated by cyclins and cyclin-dependent kinases, which provide the permission of several checkpoints such as G1/S and G2/ M. Dysregulation of checkpoint proteins including Cyclin D1, CDK4 and CDK6 have been positively correlated with HCC cell proliferation [124-126].

Not surprisingly, some lncRNAs are involved in the HCC progression by regulating such RTKs and cell cycle (Fig. 4a). For example, lnc-EGFR interacts with EGFR to lead to its constitutive activation, which promotes HCC growth [38]. EGFR can also be bound by LINC01225, therefore increasing its protein level, contributing to the activation of EGFR-Ras signaling and sustaining HCC cell proliferation [127]. Besides EGFR, other HCC-related RTKs such as c-Met, IGF1R and IGF2R have been also shown to be regulated by lncRNAs, suggesting a wide range of lncRNA-RTK regulatory network in HCC proliferation $[103,128,129]$. As to the cell cycle regulated by lncRNAs and its roles in HCC proliferation, Cao et al. reported that lncRNA UFC1 binds to mRNA stabilizing protein $\mathrm{HuR}$ to upregulate the expression of $\beta$-catenin and a series of checkpoint proteins including CDK4/6, c-Myc and cyclin D1, leading to G1/S phase transition and enhanced proliferation of HCC cell [54]. Besides, many other 


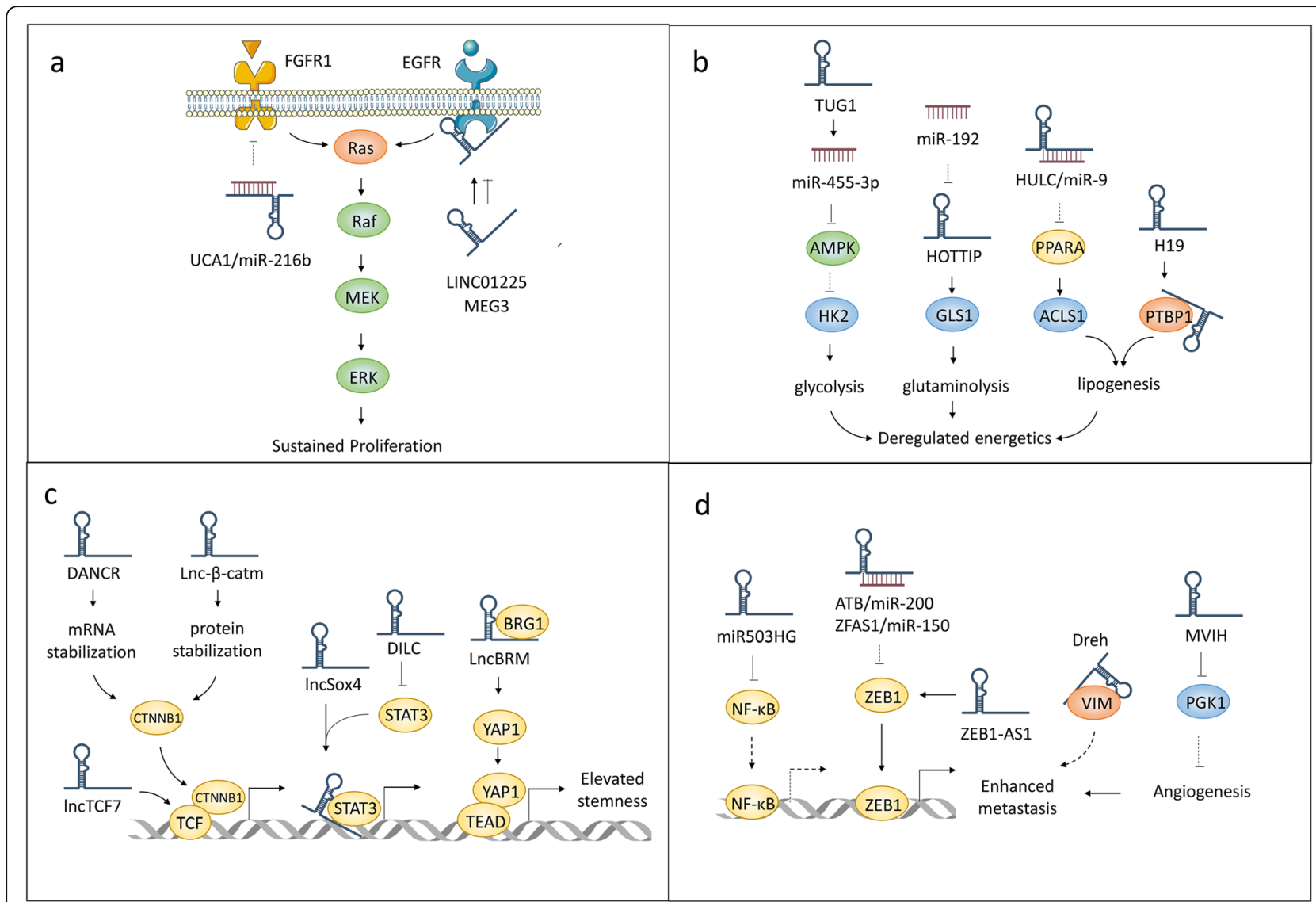

Fig. 4 Significance of IncRNA in HCC hallmarks. Dysregulated IncRNAs promote HCC through distinct mechanisms, leading to different phenotypes corresponding to every tumor stage. These hallmarks include (a) sustained proliferation due to aberrant regulation of growth factor receptor/RTK signaling or cell cycle progression; $\mathbf{b}$ dysregulated energetics induced by metabolic reprogramming; $\mathbf{c}$ elevated stemness due to the hyperactivation of CSC-related signaling; $\mathbf{d}$ enhanced metastasis induced by the overexpression of mesenchymal markers and formation of additional vessels

IncRNAs such as PVT1, Linc00974 and HEIH can also facilitate the cell cycle progression via interacting with NOP2, miR-642 and EZH2, respectively, thereby promoting the proliferation of $\mathrm{HCC}[66,130,131]$.

\section{Dysregulating cellular energetics}

Cancer cells reprogram their metabolic pathways to provide energy and building blocks. These metabolic shifts include upregulation of aerobic glycolysis, glutaminolysis, lipogenesis and so on. To be specific, aerobic glycolysis means that cancer cells prefer to glycolysis instead of mitochondrial oxidative phosphorylation even in the presence of sufficient oxygen, which is also termed as "Warburg effect", being the predominant way for energy production of cancer cells. Another metabolic shift glutaminolysis describes a biochemical reaction by which glutamine is lysed to yield a series of metabolites. This pathway is tightly related to the generation of NADPH and the proper function of cellular antioxidant machinery, facilitating cancer cell survival under oxidative stress. In addition, lipogenesis enhances membrane biosynthesis and energy storage, which is critical for cancer development [132]. Mechanistically, key metabolic enzymes usually undergo gain- or loss-offunction during those processes, which is frequently observed in most malignancies including HCC.

Particularly, lncRNA has been proposed as a critical factor in the dysregulation of metabolic enzymes and aberrant energetic mode of HCC cells, such as the upregulation of aerobic glycolysis, glutaminolysis, and lipogenesis (Fig. 4b). For instance, aerobic glycolysis can be upregulated by the activation of HK2 and the inactivation of AMPK, which have been addressed in the progression of HCC $[133,134]$. Lin et al. have recently shown that IncRNA TUG1 is capable of stimulating the transcription of miR-455-3p and downregulates the protein level of AMPK $\beta 2$ by targeting its mRNA. This LncRNA-mediated AMPK silencing reactivates the expression of HK2, resulting in an elevated glycolytic capacity of HCC cells [58]. Besides, overexpression of GLS1, which catalyze the biogenesis of glutamate, making HCC cells addicted to glutaminolysis. LncRNA HOTTIP upregulates the expression of GLS1, thereby promoting the glutaminolysis and the proliferation of HCC cells. 
Inhibition of HOTTIP by endogenous miRNAs miR-192/ 204 downregulates the expression of GLS1 and is associated with a reduced level of glutaminolysis in HCC [67]. Another metabolic switch lies in the abnormal lipid metabolism pathway. LncRNA HULC modulates lipogenesis in HCC through activating ACSL1, the subunit of acyl-CoA synthetase that produces acyl-CoAs for the lipid synthesis. Mechanistically, HULC inhibits miR-9 to reactivate the expression of PPARA, which actively transcribes ACSL1 to accumulate intracellular cholesterol and HCC progression [64]. Another IncRNA H19 can also participate in lipogenesis by interacting with PTBP1, therefore maintaining the homeostasis of lipid metabolism in hepatocytes, and deletion of H19 is sufficient to abolish liver steatosis induced by high-fat-diet, suggesting its potential roles in HCC [135].

\section{Acquiring CSC properties}

Stem cells preserve the abilities to replicate indefinitely and differentiate into specialized cell types, which are indispensable for the regeneration of damaged tissues. Liver holds remarkable regenerative capacity, where hepatic stem cells play key roles. However, cancer stem cells (CSCs) represent a major obstacle for cancer treatment and account for most cancer drug resistance and relapse. For HCC, several stemness markers such as CD133, CD24, EpCAM, ICAM-1 have been identified, and these HCC stem cells are believed to play critical roles in progression and chemoresistance of HCC [136, 137]. Importantly, multiple signalings such as Wnt- $\beta$-catenin, JAK-STAT, and Hippo-YAP pathways are involved in the maintenance of HCC stem cells. Briefly, activation of Wnt- $\beta$-catenin is associated with the expression of HCC stem cell markers such as CD133 and EpCAM, and reduced response to chemotherapeutic agents [138, 139]. Moreover, STAT3 is capable of simulating the expression of NANOG, a well-known pluripotency sustaining factor, thus promoting the expansion of CD24(+) HCC stem cells [140]. In addition, Hippo-YAP signaling controls the size of organism, the regeneration of liver, and the stemness of cells. Cai et al. reported that activation of Hippo-YAP can also increase the population of CD24(+) HCC stem cells, and is related to a more aggressive phenotype in HCC patients [141].

Accumulating evidence have suggested critical roles of IncRNAs in the regulation of Wnt- $\beta$-catenin, JAKSTAT, Hippo-YAP and other signaling pathways, affecting the stemness of HCC cells (Fig. 4c). Firstly, lncRNAs are able to regulate Wnt- $\beta$-catenin pathways in either post-transcriptional or post-translational level. For example, lncRNA DANCR binds to the mRNA of $\beta$ catenin to prevent its degradation by miRNAs, increasing the proportion of HCC cells with stemness features and elevated their tumor-seeding ability [61]. Another lncRNA lnc- $\beta$-Catm recruits EZH2 to promote the methylation of $\beta$-catenin at $\mathrm{K} 49$, inhibiting its ubiquitination and upregulates its stability, supporting the selfrenewal of HCC stem cells [59]. Interestingly, lncTCF7 activates Wnt signaling and maintains $\mathrm{HCC}$ cell stemness by directly upregulating TCF7, which is probably not related with $\beta$-catenin [142]. Secondly, IncRNAs have been shown to either upregulate or downregulate the HCC cell stemness via promoting or suppressing IL6-STAT signaling, respectively. Chen et al. have found that LncSox4 interacts with STAT3 and recruits it to the promoter of Sox4 to stimulate its transcription, conferring $\mathrm{HCC}$ cells with stem properties and results in $\mathrm{HCC}$ initiation [143]. In contrast, another IncRNA DILC functions as a tumor suppressor to inhibit the expansion of HCC stem cells via inhibiting IL6-STAT3 pathway [68]. Thirdly, Hippo signaling and its transcription cofactor YAP/TAZ are also implicated in liver CSCs. For instance, IncBRM interacts with the BRM protein to modulate the switch from BRM to BRG1 promoting the assembly of BRG1-embedded BAF complex, which activates YAP1 expression and supports self-renewal of HCC stem cells [144]. In addition, other lncRNAs such as PVT1 and ICR have been also shown to upregulate the stemness of HCC cells through binding with NOP2 protein and ICAM-1 mRNA, respectively, leading to HCC progression and predicting poor clinical outcomes $[66,69]$.

\section{Activating invasion and metastasis}

Tumor metastasis causes the great majority of cancerrelated death. Briefly, metastasis begins with epithelialmesenchymal transition (EMT) program where epithelial marks (E-cadherin, ZO-1, etc.) are downregulated and mesenchymal marks (vimentin, ZEB1, etc.) are overexpressed within cells. Then mesenchymal-like cells invade into vessels where some of them become anoikis resistant and translocate to distant organ to form metastases. Particularly, the metastasis of HCC shares considerable similarities with other cancer types, whereas EMT program and enhanced angiogenesis have been addressed as critical events driving HCC metastasis [145, 146].

Several lncRNAs are capable of regulating the expression of certain EMT markers and the formation of additional blood vessels, affecting HCC metastasis (Fig. 4d). For example, two lncRNAs ATB and ZFAS1 are capable of sponging miR-200 and miR-150, respectively. It allows for the reactivation of ZEB1, a mesenchymal mark that inhibits E-cad expression, thus promoting the metastasis of HCC $[40,70]$. Besides miRNA sponge, lncRNAs can also directly regulate the expression of ZEB1 without involving miRNAs. One of such cases is that lncRNA ZEB1-AS1 stimulates the expression of ZEB1 by elevating its promoter activity thus promoting the metastasis of HCC, and patients with ZEB1-AS1 hypomethylation 
are associated with high metastatic recurrence and poor survival [147]. Moreover, another key mesenchymal mark vimentin can interact with lncRNA Dreh, which functions as a tumor suppressor in HCC. This binding disrupts the cytoskeleton structure, leading to the suppression of HCC metastasis [24]. As to the roles of lncRNA-mediated regulation of angiogenesis during HCC metastasis, Yu et al. reported that lncRNA MVIH represses the secretion of PGK1, an inhibitory regulator of angiogenesis, therefore promoting the vessel formation and HCC metastasis [71]. Importantly, it has been widely accepted that hypoxia largely contributes to tumor angiogenesis, at least partly due to the overexpression of HIF proteins. This process involves lncRNA LET, which has been found to downregulate the expression of HIF- $1 \alpha$ thereby suppressing hypoxia-mediated HCC metastasis [44]. It is worth mentioning that many other lncRNAs, including FTX, MUF, miR503HG, NEF, TSLNC8, etc. are capable of regulating HCC metastasis through distinct mechanisms, which have been described elsewhere [101, 102, 148-150].

\section{Diagnostic and therapeutic potentials of IncRNA in HCC}

To date, the diagnosis of HCC largely relies on ultrasonography imaging and AFP measurement. Indeed, highrisk populations are recommended to perform ultrasonography screening, and those patients who received more frequent imaging have been associated with better survival [151]. However, this surveillance imaging is inadequate to visualize early stage HCC with only $47 \%$ sensitivity [152]. Besides, the widely used HCC biomarker AFP has $52.9 \%$ sensitivity and $93.3 \%$ specificity, which can be further improved when combined with ultrasonography imaging [153]. However, other factors such as HCV infection has been shown to elevate AFP level in the absence of HCC [154]. Furthermore, a recent study even suggested that neither ultrasonography imaging nor AFP measurement decreases the mortality of HCC patients [155]. Apart from lacking reliable biomarkers, limited therapeutic options also contribute to HCC-related death. Currently, surgical methods such as resection and liver transplantation are the only possible curative approaches for early $\mathrm{HCC}$, while $\mathrm{HCC}$ in late stage is largely incurable. Therefore, novel biomarkers and therapeutic targets are urgently needed for improving the diagnosis and treatment of HCC.

\section{LncRNAs are potential biomarkers for HCC diagnosis}

As previously discussed, a large number of lncRNAs are aberrantly expressed in HCC compared with normal liver tissue, which is useful to distinguish HCC patients from healthy cohorts. However, some of those lncRNAs are also shown aberrant expression patterns in other cancer types or non-cancerous situations such as cirrhosis or liver injury, resulting in reduced reliability. Thus, IncRNAs combined with other molecules, especially known HCC biomarker AFP, is more likely to be a desirable HCC diagnosis method instead of evaluating lncRNAs alone. For instance, the combination of two lncRNAs UCA1 and WRAP53 with AFP achieves sensitivity up to $100 \%$ [20]. Similarly, the combination of another two lncRNAs PVT1 and uc002mbe. 2 with AFP have been also shown to perform much better than AFP alone in HCC diagnosis [156]. Besides AFP, other molecules including miRNAs or mRNAs can also predict HCC in combination with lncRNAs, which have been reviewed elsewhere [157]. In addition to their diagnostic value, various lncRNAs might also be potential prognostic markers in HCC. For instance, aforementioned lncRNA WRAP53 is also an independent prognostic biomarker to predict high relapse rate of HCC patients [20]. Not surprisingly, lncRNAs involved in tumor metastasis might well hold prognostic value. For example, IncRNA-ATB, which is upregulated in HCC metastases, predicts poor prognosis of HCC patients [40]. In contrast, lncRNA miR503HG with metastasis-suppressing function is a favorable prognostic indicator [148].

Compared with sampling solid tumor tissues, liquid biopsy is largely non-invasive thus being an ideal diagnostic approach. Importantly, several HCC-related lncRNAs can be present in the body fluid (circulating lncRNAs), as is the case with aforementioned IncRNAs UCA1, WRAP53, PVT1 and uc002mbe.2. Also, the representative HCCpromoting lncRNA HULC is detectable in blood sample and can be easily quantified by conventional real-time qPCR [17]. These findings have suggested a noninvasive approach for HCC diagnosis through circulating lncRNA measurement. Further studies have revealed that these circulating lncRNAs origin from the secretion of exosomes or other extracellular vesicles (EVs) such as microvesicles and apoptotic bodies, which protect them from RNasemediated degradation in body fluid [158, 159]. One of such examples is linc-RoR, a hypoxia-responsive lncRNA that released from HCC cells by EVs [43]. This EVmediated lncRNA transferring contributes to rapid cellto-cell communication and intercellular signaling transduction. Furthermore, these EV-engulfed lncRNAs can be isolated from body fluid by various methods such as ultracentrifugation and ultrafiltration, providing efficient tools to analyze circulating lncRNAs that possibly serve as HCC biomarkers [160].

\section{LncRNAs as promising HCC therapeutic targets}

To date, the prognosis of HCC is overall poor, which is at least in part due to lack of therapeutic target. The most used targeted drug in HCC is sorafenib that targeting RTKs, however, sorafenib resistance is frequently observed during HCC treatment [161]. Thus, novel target 
is required for improving the prognosis of $\mathrm{HCC}$ patients. The critical roles of lncRNAs in HCC make them promising drug targets for novel therapeutic interventions. Furthermore, lncRNA-targeting approaches hold some advantages over protein-targeting methods in terms of base-pairing principle is much more straightforward than designing a specific protein-binding inhibitor. These lncRNA-targeting approaches mainly include antisense oligonucleotides (ASOs) and RNA interference (RNAi), both of which have been shown favorable anticancer activities against HCC via targeting lncRNAs. For instance, ASO-mediated linc00210 silence has been shown to repress the self-renewal and invasion of HCC cells, and knockdown of IncRNA CASC9 by RNAi significantly reduced the tumor formation in a HCC mouse model [72, 162]. Briefly, ASOs are short single-stranded DNAs that bind to target lncRNA to form DNA-RNA complex, which can be recognized and cleaved by RNase $\mathrm{H}$. In contrast, RNAi are short double-stranded RNAs that have to be loaded into AGO2 protein to form an RNA-induced silencing complex (RISC), then interact with target lncRNA to yield RNA-RNA complex and mediate lncRNA silence [163]. In view of these differences, ASOs and RNAi probably display distinct silencing efficiency upon various factors, such as the subcellular location of target lncRNAs. Lennox et al. reported that ASOs function better than RNAi in nuclei, whereas RNAi is more effective than ASOs for targeting cytoplasmic IncRNAs [164]. It can be at least partially due to the fact that RNase $\mathrm{H}$ is mainly present in nuclei while RISC predominantly function in the cytoplasm [92, 165]. Besides knockdown of oncogenic lncRNAs, delivery of tumor suppressive IncRNAs can be an alternative strategy. For instance, lncRNA PRAL serves as a tumor suppressor through stabilizing p53, and gene delivery of PRAL through adenovirus vector has been shown to significantly inhibit HCC growth in tumor-bearing mice, suggesting its potential clinic value for HCC treatment [73]. It is worth noted that the current pipeline of HCC-targeted ASOs and RNAi is broad, for both of which have been already applied in the treatment of HBV. Briefly, ASOs and siRNAs are modified by chemical conjugates (such as N-acetylgalactosamine, GalNAc) [166] or formulated in delivery vehicles (such as lipid nanoparticles) [167], thereby achieving an optimized pharmacokinetic profile. These commercial experiences in HBV treatment using ASOs and RNAi provide a substantial basis for lncRNA interference and HCC therapy.

\section{Conclusions}

Cancer relevant lncRNAs are gradually becoming one of the hottest issues in the RNA biology and oncology. Current evidences reveal that aberrant transcription or processing events can lead to the upregulation of oncogenic lncRNAs or silence of tumor suppressive lncRNAs, which bind to DNA, RNA or proteins. As a result, lncRNAs regulate the expression, localization, stability, activity and other properties of their binding partners, raising a series of cancerous phenotypes such as persistent proliferation, abnormal metabolism, elevated stemness and metastasis, leading to tumorigenesis and progression of HCC. In terms of their crucial roles, a part of lncRNAs that present in body fluid hold value of serving as potential HCC biomarkers alone with high sensitivity, or in combination with other molecules to improve specificity. Thus, modulation of lncRNA expression can be a novel therapeutic strategy for the treatment of HCC.

Though remarkable progress has been achieved in this field, the functions of most lncRNAs are still elusive. The lack of functional studies sometimes challenges the importance of lncRNAs, which can be partially due to their overall less sequence conservation compared with protein-coding genes [168]. Nevertheless, IncRNAs tend to maintain evolutionarily conserved secondary structure in the present of considerable sequence variation [169]. Moreover, it has been proposed that selective pressure may act on lncRNAs at the secondary structure to constrain sequence variation, which depletes mutations in structural regions with low fitness [170]. These findings suggest that sequence polymorphism may not be selected if it does not induce significant structural alterations, resulting in a lack of sequence conservation of IncRNAs. In contrast, sequence conservation of protein-coding genes is much higher, for the insert or deletion of even a single nucleotide is sufficient to result in frameshift and complete loss of function. Thus, for lncRNAs, secondary structure might serve as not only evolutionary constraint, but also the main functional unit to participate in biological processes, including HCC progression. For instance, the three stem-loop structure in lncRNA PRAL is required for its function as the molecular scaffold and tumor suppressor against HCC [73]. Together, these findings suggest that the function of lncRNAs might also be largely determined by their secondary structure in addition to the primary sequence. However, the secondary structure of lncRNAs seems to receive no enough interest, not to mention revealing the connection between lncRNA secondary structure and their biological functions. In contrast, RNA modifications, especially N6-methyladenosine (m6A) has received more attention and become a new research hotspot in the functional study of lncRNA. The well-known lncRNA Xist is one of such lncRNAs undergo m6A modification, which is critical for its function to mediate transcriptional repression [171]. Mechanistic studies revealed that $\mathrm{m} 6 \mathrm{~A}$ frequently regulates the degradation of modified lncRNAs, including those related with HCC. For example, m6A modification upregulates the stability of LINC00958, leading to its overexpression in HCC and promotes cell proliferation and invasion [172]. This effect may 
result from an enhanced binding of lncRNA with protective partner, or a disassociation with RNA decay machinery. In fact, m6A modification results in structural changes on lncRNAs, which regulate the interaction between them and their binding partners [173]. As mention above that lncRNAs largely function through their binding partners, the regulation of lncRNAs by m6A modification should be comprehensive and ubiquitous.

Another concern is the lack of lncRNA knockout animal model, which can be attributed to many reasons. As previously discussed, IncRNAs are impervious to sequence mutations, which means that certain genetic perturbations used to knockout protein-coding genes may not function well when applied to knockout lncRNAs. Besides, many lncRNAs have overlap with proteincoding genes, making it difficult to specifically knockout a lncRNA without affecting overlapping genes. As a result, knockdown of lncRNAs at the transcription level (e.g. ASOs and RNAi as described above) has been used as an alternative strategy to investigate their functions in vivo. However, this knockdown method may not be sufficient to eliminate lncRNAs compared with a knockout approach, and the introduction of exogenous molecules may be toxic to organisms and induce off-target effects [174]. Therefore, IncRNA knockout mouse models are more reliable and necessary for revealing their functions, whereas no such models have been used in the studies of HCC so far. Notably, some possible lncRNA knockout methods have been proposed including the deletion of lncRNA genes completely as the conventional strategy, deletion of lncRNA promoter to prevent transcription, and insert of polyadenylation signal to terminate the transcription at the outset [175]. Moreover, lncRNA knockout mice have been used in other cancer types such as melanoma and noncancerous biological processes such as brain development [176, 177]. Therefore, this model will be certainly used to facilitate the investigation of $\mathrm{HCC}$ in the near future.

\footnotetext{
Abbreviations

IncRNA: long noncoding RNA; HCC: Hepatocellular carcinoma; HBV: Hepatitis B virus; HCV: Hepatitis C virus; NAFLD: Non-alcoholic fatty liver disease; AFP: A-fetoprotein; ncRNA: noncoding RNA; siRNA: small interfering RNA; miRNA: microRNA; piRNA: PIWl-interacting RNA; ROS: Reactive oxygen species; XIST: X-inactive-specific transcript; HULC: Hepatocellular carcinoma up-regulated long non-coding RNA; MALAT1: Metastasis-associated lung adenocarcinoma transcript 1; MEN $\beta$ : Multiple endocrine neoplasia $\beta$; MEG3: Maternally expressed gene 3; PXN-AS1: PXN antisense transcript 1; circRNA: circular RNA; TUG1: Taurine-upregulated gene 1; RUNXOR: RUNX1 overlapping RNA; TINCR: Terminal differentiation-induced ncRNA; THOR: Testis-associated highly conserved oncogenic long non-coding RNA; Mhrt: Myosin heavy-chain-associated RNA transcripts; ANRIL: CDKN2B antisense RNA 1 ; Inc- $\beta$-Catm: IncRNA for $\beta$-catenin methylation; GIHCG: Gradually increased during hepatocarcinogenesis; UCA1: Urothelial cancer associated 1; UFC1: Ubiquitin-fold modifier conjugating enzyme 1; DANCR: Anti-differentiation ncRNA; CASC9: Cancer Susceptibility 9; RTK: Receptor tyrosine kinase; HOTTIP: HOXA distal transcript antisense RNA CSC: Cancer stem cell; DILC: Downregulated in liver cancer stem cells; PVT1: Plasmacytoma variant translocation 1; ATB: IncRNA-activated by TGF- $\beta$;
}

ZFAS1: ZNFX1 antisense RNA 1; Dreh: IncRNA down-regulated expression by HBX; MVIH: IncRNA associated with microvascular invasion in HCC; PSTAR: p53-stabilizing and activating RNA; HDGF: Hepatoma-derived growth factor; WRAP53: WD repeat containing, antisense to TP53; IFI6: Interferon Alpha-Inducible Protein 6; CMPK2: CMP kinase 2; EGOT: Eosinophil granule ontogeny transcript; LINE1: Long interspersed nuclear elements 1; LALR1: Long noncoding RNAs associated with liver regeneration 1; DSCR8: Down syndrome critical region 8; SNHG5: Small nucleolar RNA host gene 5; NEAT1: Nuclear-enriched abundant transcript 1; RoR: Regulator of reprogramming; LET: Low Expression in Tumor; Khps1: Antisense orientation to the proto-oncogene SPHK1; UPAT: UHRF1 Protein Associated Transcript: HOTAIR: HOX Antisense Intergenic RNA; FTX: An XIST regulator transcribed from the $X$ chromosome inactivation center; MUF: MSC-upregulated factor; FAL1: Focally amplified IncRNA on chromosome 1; IncKdm2b: a divergent IncRNA for Kdm2b gene; NORAD: Noncoding RNA activated by DNA damage; PRAL: p53 regulation-associated IncRNA; ENOD40: Early nodulin 40; NCBP2-AS2: NCBP2-antisense 2; HEIH: Long noncoding RNA high expression in hepatocellular carcinoma; ICR: ICAM-1-Related Noncoding RNA; ZEB1AS1: ZEB1 antisense 1; miR503HG: the host gene of miR503; NEF: TSLNC8, tumor suppressor long noncoding RNA on chromosome $8 \mathrm{p} 12$

\section{Acknowledgements}

Not applicable.

\section{Authors' contributions}

$\mathrm{CH}, \mathrm{WH}$ and $\mathrm{YP}$ conceived the structure of manuscript and revised the manuscript. ZH drafted initial manuscript. JKZ made the figures and table. All authors read and approved the final manuscript.

\section{Funding}

This work was supported by grants from the National Natural Science Foundation of China (81821002, 81790251, 81430071 and 81672381),

Guangdong Basic and Applied Basic Research Foundation (2019B030302012), the National 973 Basic Research Program of China (2013CB911300),

Fundamental Research Funds for the Central Universities (2018SCUH0018), Department of Sichuan Science \& Technology Program (2019JDTD0013), and The 1.3.5 Project for Disciplines of Excellence, West China Hospital, Sichuan University (ZYJC18030).

\section{Availability of data and materials}

All the data obtained and/or analyzed during the current study were available from the corresponding authors on reasonable request.

\section{Ethics approval and consent to participate}

Not applicable.

\section{Consent for publication}

All authors give consent for the publication of manuscript in Molecular Cancer.

\section{Competing interests}

The authors declare that they have no competing interests.

Received: 1 January 2020 Accepted: 19 March 2020

Published online: 15 April 2020

\section{References}

1. Bertuccio P, Turati F, Carioli G, Rodriguez T, La Vecchia C, Malvezzi M, et al. Global trends and predictions in hepatocellular carcinoma mortality. J Hepatol. 2017;67(2):302-9..

2. Forner A, Llovet JM, Bruix J. Hepatocellular carcinoma. Lancet. 2012 ; 379(9822):1245-55.

3. Cancer Genome Atlas Research Network, Electronic address wbe, Cancer Genome Atlas Research N. Comprehensive and integrative genomic characterization of hepatocellular carcinoma. Cell. 2017;169(7):1327-41 e23.

4. Nishida N, Nagasaka T, Nishimura T, Ikai I, Boland CR, Goel A. Aberrant methylation of multiple tumor suppressor genes in aging liver, chronic hepatitis, and hepatocellular carcinoma. Hepatology. 2008;47(3):908-18.

5. Dang $H$, Takai A, Forgues M, Pomyen $Y$, Mou H, Xue W, et al. Oncogenic activation of the RNA binding protein NELFE and MYC signaling in hepatocellular carcinoma. Cancer Cell. 2017;32(1):101-14 e8. 
6. Rovida E, Di Maira G, Tusa I, Cannito S, Paternostro C, Navari N, et al. The mitogen-activated protein kinase ERK5 regulates the development and growth of hepatocellular carcinoma. Gut. 2015;64(9):1454-65.

7. Chang MH, You SL, Chen CJ, Liu CJ, Lai MW, Wu TC, et al. Long-term effects of hepatitis B immunization of infants in preventing liver cancer. Gastroenterology. 2016;151(3):472-80 e1.

8. Bruix J, Qin S, Merle P, Granito A, Huang YH, Bodoky G, et al. Regorafenib for patients with hepatocellular carcinoma who progressed on sorafenib treatment (RESORCE): a randomised, double-blind, placebo-controlled, phase 3 trial. Lancet. 2017:389(10064):56-66.

9. Kokudo T, Hasegawa K, Matsuyama Y, Takayama T, Izumi N, Kadoya M, et al. Survival benefit of liver resection for hepatocellular carcinoma associated with portal vein invasion. J Hepatol. 2016;65(5):938-43.

10. Clavien PA, Lesurtel M, Bossuyt PM, Gores GJ, Langer B, Perrier A, et al. Recommendations for liver transplantation for hepatocellular carcinoma: an international consensus conference report. Lancet Oncol. 2012;13(1):e11-22.

11. Rosenbloom KR, Dreszer TR, Long JC, Malladi VS, Sloan CA, Raney BJ, et al. ENCODE whole-genome data in the UCSC genome browser: update 2012 Nucleic Acids Res. 2012:40(Database issue):D912-7.

12. Gabory A, Ripoche MA, Le Digarcher A, Watrin F, Ziyyat A, Forne T, et al. $\mathrm{H} 19$ acts as a trans regulator of the imprinted gene network controlling growth in mice. Development. 2009;136(20):3413-21.

13. Brannan $\mathrm{Cl}$, Dees EC, Ingram RS, Tilghman SM. The product of the H19 gene may function as an RNA. Mol Cell Biol. 1990;10(1):28-36.

14. Brown CJ, Lafreniere RG, Powers VE, Sebastio G, Ballabio A, Pettigrew AL, et al. Localization of the $X$ inactivation Centre on the human $X$ chromosome in Xq13. Nature. 1991;349(6304):82-4.

15. Iyer MK, Niknafs YS, Malik R, Singhal U, Sahu A, Hosono Y, et al. The landscape of long noncoding RNAs in the human transcriptome. Nat Genet. 2015;47(3):199-208.

16. Yang Y, Chen L, Gu J, Zhang H, Yuan J, Lian Q, et al. Recurrently deregulated IncRNAs in hepatocellular carcinoma. Nat Commun. 2017;8: 14421.

17. Panzitt K, Tschernatsch MM, Guelly C, Moustafa T, Stradner M, Strohmaier HM, et al. Characterization of HULC, a novel gene with striking upregulation in hepatocellular carcinoma, as noncoding RNA. Gastroenterology. 2007;132(1):330-42.

18. Li D, Liu X, Zhou J, Hu J, Zhang D, Liu J, et al. Long noncoding RNA HULC modulates the phosphorylation of YB-1 through serving as a scaffold of extracellular signal-regulated kinase and YB-1 to enhance hepatocarcinogenesis. Hepatology. 2017;65(5):1612-27.

19. Klec C, Gutschner T, Panzitt K, Pichler M. Involvement of long non-coding RNA HULC (highly up-regulated in liver cancer) in pathogenesis and implications for therapeutic intervention. Expert Opin Ther Targets. 2019; 23(3):177-86.

20. Kamel MM, Matboli M, Sallam M, Montasser IF, Saad AS, El-Tawdi AHF. Investigation of long noncoding RNAs expression profile as potential serum biomarkers in patients with hepatocellular carcinoma. Transl Res. 2016;168: $134-45$

21. Tang LSY, Covert E, Wilson E, Kottilil S. Chronic hepatitis B infection: a review. JAMA. 2018:319(17):1802-13.

22. Heffernan A, Cooke GS, Nayagam S, Thursz M, Hallett TB. Scaling up prevention and treatment towards the elimination of hepatitis C: a global mathematical model. Lancet. 2019;393(10178):1319-29.

23. Liu N, Liu Q, Yang X, Zhang F, Li X, Ma Y, et al. Hepatitis B virus-upregulated LNC-HUR1 promotes cell proliferation and tumorigenesis by blocking p53 activity. Hepatology. 2018;68(6):2130-44

24. Huang JF, Guo YJ, Zhao CX, Yuan SX, Wang Y, Tang GN, et al. Hepatitis B virus $X$ protein (HBX)-related long noncoding RNA (IncRNA) down-regulated expression by HBx (Dreh) inhibits hepatocellular carcinoma metastasis by targeting the intermediate filament protein vimentin. Hepatology. 2013; 57(5):1882-92.

25. Liu X, Duan X, Holmes JA, Li W, Lee SH, Tu Z, et al. A long noncoding RNA regulates hepatitis $C$ virus infection through interferon alpha-inducible protein 6. Hepatology. 2019;69(3):1004-19.

26. Kambara H, Niazi F, Kostadinova L, Moonka DK, Siegel CT, Post AB, et al. Negative regulation of the interferon response by an interferon-induced long non-coding RNA. Nucleic Acids Res. 2014;42(16):10668-80.

27. Carnero E, Barriocanal M, Prior C, Pablo Unfried J, Segura V, Guruceaga E, et al. Long noncoding RNA EGOT negatively affects the antiviral response and favors HCV replication. EMBO Rep. 2016;17(7):1013-28.
28. Lau CC, Sun T, Ching AK, He M, Li JW, Wong AM, et al. Viral-human chimeric transcript predisposes risk to liver cancer development and progression. Cancer Cell. 2014;25(3):335-49.

29. Mars WM, Liu ML, Kitson RP, Goldfarb RH, Gabauer MK, Michalopoulos GK. Immediate early detection of urokinase receptor after partial hepatectomy and its implications for initiation of liver regeneration. Hepatology. 1995; 21(6):1695-701.

30. Michalopoulos GK. Liver regeneration after partial hepatectomy: critical analysis of mechanistic dilemmas. Am J Pathol. 2010;176(1):2-13.

31. Tan X, Apte U, Micsenyi A, Kotsagrelos E, Luo JH, Ranganathan S, et al. Epidermal growth factor receptor: a novel target of the Wnt/beta-catenin pathway in liver. Gastroenterology. 2005;129(1):285-302.

32. Zhang $Y$, Xia M, Jin K, Wang $S$, Wei H, Fan C, et al. Function of the c-met receptor tyrosine kinase in carcinogenesis and associated therapeutic opportunities. Mol Cancer. 2018;17(1):45.

33. Michalopoulos GK. Liver regeneration. J Cell Physiol. 2007;213(2):286-300.

34. Xu D, Yang F, Yuan JH, Zhang L, Bi HS, Zhou CC, et al. Long noncoding RNAs associated with liver regeneration 1 accelerates hepatocyte proliferation during liver regeneration by activating Wnt/beta-catenin signaling. Hepatology. 2013;58(2):739-51.

35. Wang Y, Zhu P, Wang J, Zhu X, Luo J, Meng S, et al. Long noncoding RNA IncHand2 promotes liver repopulation via c-met signaling. J Hepatol. 2018; 69(4):861-72.

36. Wang Y, Sun L, Wang L, Liu Z, Li Q, Yao B, et al. Long non-coding RNA DSCR8 acts as a molecular sponge for miR-485-5p to activate Wnt/beta-catenin signal pathway in hepatocellular carcinoma. Cell Death Dis. 2018;9(9):851.

37. Li Y, Guo D, Zhao Y, Ren M, Lu G, Wang Y, et al. Long non-coding RNA SNHG5 promotes human hepatocellular carcinoma progression by regulating miR26a-5p/GSK3beta signal pathway. Cell Death Dis. 2018;9(9):888.

38. Jiang R, Tang J, Chen $Y$, Deng $L$, Ji J, Xie $Y$, et al. The long noncoding RNA Inc-EGFR stimulates T-regulatory cells differentiation thus promoting hepatocellular carcinoma immune evasion. Nat Commun. 2017:8:15129.

39. Chen S, Xia X. Long noncoding RNA NEAT1 suppresses sorafenib sensitivity of hepatocellular carcinoma cells via regulating miR-335-c-met. J Cell Physiol. 2019. https://doi.org/10.1002/jcp.27567.

40. Yuan JH, Yang F, Wang F, Ma JZ, Guo YJ, Tao QF, et al. A long noncoding RNA activated by TGF-beta promotes the invasion-metastasis cascade in hepatocellular carcinoma. Cancer Cell. 2014;25(5):666-81.

41. Ebert EC. Hypoxic liver injury. Mayo Clin Proc. 2006;81(9):1232-6.

42. Zhu AX, Duda DG, Sahani DV, Jain RK. HCC and angiogenesis: possible targets and future directions. Nat Rev Clin Oncol. 2011;8(5):292-301.

43. Takahashi K, Yan IK, Haga H, Patel T. Modulation of hypoxia-signaling pathways by extracellular linc-RoR. J Cell Sci. 2014;127(Pt 7):1585-94.

44. Yang F, Huo XS, Yuan SX, Zhang L, Zhou WP, Wang F, et al. Repression of the long noncoding RNA-LET by histone deacetylase 3 contributes to hypoxia-mediated metastasis. Mol Cell. 2013;49(6):1083-96.

45. Li S, Tan HY, Wang N, Zhang ZJ, Lao L, Wong CW, et al. The role of oxidative stress and antioxidants in liver diseases. Int J Mol Sci. 2015;16(11): 26087-124.

46. Derrien T, Johnson R, Bussotti G, Tanzer A, Djebali S, Tilgner $H$, et al. The GENCODE v7 catalog of human long noncoding RNAs: analysis of their gene structure, evolution, and expression. Genome Res. 2012;22(9):1775-89.

47. Wu SC, Kallin EM, Zhang Y. Role of H3K27 methylation in the regulation of IncRNA expression. Cell Res. 2010;20(10):1109-16.

48. Mele M, Mattioli K, Mallard W, Shechner DM, Gerhardinger C, Rinn JL. Chromatin environment, transcriptional regulation, and splicing distinguish lincRNAs and mRNAs. Genome Res. 2017;27(1):27-37.

49. Alcid EA, Tsukiyama T. ATP-dependent chromatin remodeling shapes the long noncoding RNA landscape. Genes Dev. 2014;28(21):2348-60.

50. Sigova AA, Mullen AC, Molinie B, Gupta S, Orlando DA, Guenther MG, et al. Divergent transcription of long noncoding RNA/mRNA gene pairs in embryonic stem cells. Proc Natl Acad Sci U S A. 2013;110(8):2876-81.

51. Wong CM, Tsang FH, Ng IO. Non-coding RNAs in hepatocellular carcinoma: molecular functions and pathological implications. Nat Rev Gastroenterol Hepatol. 2018;15(3):137-51

52. Wilusz JE, JnBaptiste CK, Lu LY, Kuhn CD, Joshua-Tor L, Sharp PA. A triple helix stabilizes the $3^{\prime}$ ends of long noncoding RNAs that lack poly(a) tails. Genes Dev. 2012;26(21):2392-407.

53. Brown JA, Valenstein ML, Yario TA, Tycowski KT, Steitz JA. Formation of triple-helical structures by the 3'-end sequences of MALAT1 and MENbeta noncoding RNAs. Proc Natl Acad Sci U S A. 2012;109(47):19202-7. 
54. Cao C, Sun J, Zhang D, Guo X, Xie L, Li X, et al. The long intergenic noncoding RNA UFC1, a target of MicroRNA 34a, interacts with the mRNA stabilizing protein HuR to increase levels of beta-catenin in HCC cells. Gastroenterology. 2015;148(2):415-26 e18.

55. Yuan JH, Liu XN, Wang TT, Pan W, Tao QF, Zhou WP, et al. The MBNL3 splicing factor promotes hepatocellular carcinoma by increasing PXN expression through the alternative splicing of IncRNA-PXN-AS1. Nat Cell Biol. 2017;19(7):820-32

56. Huang MD, Chen WM, Qi FZ, Xia R, Sun M, Xu TP, et al. Long non-coding RNA ANRIL is upregulated in hepatocellular carcinoma and regulates cell apoptosis by epigenetic silencing of KLF2. J Hematol Oncol. 2015;8:50.

57. Huang MD, Chen WM, Qi FZ, Sun M, Xu TP, Ma P, et al. Long non-coding RNA TUG1 is up-regulated in hepatocellular carcinoma and promotes cell growth and apoptosis by epigenetically silencing of KLF2. Mol Cancer. 2015;14:165.

58. Lin $\mathrm{YH}, \mathrm{Wu} \mathrm{MH}$, Huang $\mathrm{YH}$, Yeh $\mathrm{CT}$, Cheng ML, Chi HC, et al. Taurine upregulated gene 1 functions as a master regulator to coordinate glycolysis and metastasis in hepatocellular carcinoma. Hepatology. 2018;67(1):188-203.

59. Zhu P, Wang Y, Huang G, Ye B, Liu B, Wu J, et al. Lnc-beta-Catm elicits EZH2-dependent beta-catenin stabilization and sustains liver CSC selfrenewal. Nat Struct Mol Biol. 2016;23(7):631-9.

60. Sui CJ, Zhou YM, Shen WF, Dai BH, Lu JJ, Zhang MF, et al. Long noncoding RNA GIHCG promotes hepatocellular carcinoma progression through epigenetically regulating miR-200b/a/429. J Mol Med (Berl). 2016;94(11): 1281-96.

61. Yuan SX, Wang J, Yang F, Tao QF, Zhang J, Wang LL, et al. Long noncoding RNA DANCR increases stemness features of hepatocellular carcinoma by derepression of CTNNB1. Hepatology. 2016;63(2):499-511.

62. Chen L, Yao H, Wang K, Liu X. Long non-coding RNA MALAT1 regulates ZEB1 expression by sponging miR-143-3p and promotes hepatocellular carcinoma progression. J Cell Biochem. 2017;118(12):4836-43.

63. Wang Y, Chen F, Zhao M, Yang Z, Li J, Zhang S, et al. The long noncoding RNA HULC promotes liver cancer by increasing the expression of the HMGA2 oncogene via sequestration of the microRNA-186. J Biol Chem. 2017;292(37):15395-407.

64. Cui M, Xiao Z, Wang $Y$, Zheng $M$, Song T, Cai X, et al. Long noncoding RNA HULC modulates abnormal lipid metabolism in hepatoma cells through an miR-9-mediated RXRA signaling pathway. Cancer Res. 2015;75(5):846-57.

65. Zhuang LK, Yang YT, Ma X, Han B, Wang ZS, Zhao QY, et al. MicroRNA-92b promotes hepatocellular carcinoma progression by targeting Smad7 and is mediated by long non-coding RNA XIST. Cell Death Dis. 2016;7:e2203.

66. Wang F, Yuan JH, Wang SB, Yang F, Yuan SX, Ye C, et al. Oncofetal long noncoding RNA PVT1 promotes proliferation and stem cell-like property of hepatocellular carcinoma cells by stabilizing NOP2. Hepatology. 2014;60(4): 1278-90.

67. Ge Y, Yan X, Jin Y, Yang X, Yu X, Zhou L, et al. MiRNA-192 [corrected] and miRNA-204 directly suppress InCRNA HOTTIP and interrupt GLS1-mediated glutaminolysis in hepatocellular carcinoma. PLoS Genet. 2015;11(12): e1005726.

68. Wang X, Sun W, Shen W, Xia M, Chen C, Xiang D, et al. Long non-coding RNA DILC regulates liver cancer stem cells via IL-6/STAT3 axis. J Hepatol. 2016;64(6):1283-94.

69. Guo W, Liu S, Cheng Y, Lu L, Shi J, Xu G, et al. ICAM-1-related noncoding RNA in cancer stem cells maintains ICAM-1 expression in hepatocellular carcinoma. Clin Cancer Res. 2016;22(8):2041-50.

70. Li T, Xie J, Shen $C$, Cheng D, Shi Y, Wu Z, et al. Amplification of long noncoding RNA ZFAS1 promotes metastasis in hepatocellular carcinoma. Cancer Res. 2015;75(15):3181-91.

71. Yuan SX, Yang F, Yang Y, Tao QF, Zhang J, Huang G, et al. Long noncoding RNA associated with microvascular invasion in hepatocellular carcinoma promotes angiogenesis and serves as a predictor for hepatocellular carcinoma patients' poor recurrence-free survival after hepatectomy. Hepatology. 2012;56(6):2231-41.

72. Klingenberg M, Gross M, Goyal A, Polycarpou-Schwarz M, Miersch T, Ernst AS, et al. The IncRNA CASC9 and RNA binding protein HNRNPL form a complex and co-regulate genes linked to AKT signaling. Hepatology. 2018;68:1817-32.

73. Zhou CC, Yang F, Yuan SX, Ma JZ, Liu F, Yuan JH, et al. Systemic genome screening identifies the outcome associated focal loss of long noncoding RNA PRAL in hepatocellular carcinoma. Hepatology. 2016;63(3):850-63.

74. Yuan SX, Zhang J, Xu QG, Yang Y, Zhou WP. Long noncoding RNA, the methylation of genomic elements and their emerging crosstalk in hepatocellular carcinoma. Cancer Lett. 2016;379(2):239-44.
75. Braconi C, Kogure T, Valeri N, Huang N, Nuovo G, Costinean S, et al. microRNA-29 can regulate expression of the long non-coding RNA gene MEG3 in hepatocellular cancer. Oncogene. 2011;30(47):4750-6.

76. Tang J, Xie $Y, X u X$, Yin $Y$, Jiang $R$, Deng $L$, et al. Bidirectional transcription of Linc00441 and RB1 via H3K27 modification-dependent way promotes hepatocellular carcinoma. Cell Death Dis. 2017;8(3):e2675.

77. Zheng GX, Do BT, Webster DE, Khavari PA, Chang HY. Dicer-microRNA-Myc circuit promotes transcription of hundreds of long noncoding RNAs. Nat Struct Mol Biol. 2014;21(7):585-90.

78. Tran DDH, Kessler C, Niehus SE, Mahnkopf M, Koch A, Tamura T. Myc target gene, long intergenic noncoding RNA, Linc00176 in hepatocellular carcinoma regulates cell cycle and cell survival by titrating tumor suppressor microRNAs. Oncogene. 2018;37(1):75-85.

79. Li Z, Zhang J, Liu X, Li S, Wang Q, Di C, et al. The LINC01138 drives malignancies via activating arginine methyltransferase 5 in hepatocellular carcinoma. Nat Commun. 2018;9(1):1572.

80. Mondal T, Subhash S, Vaid R, Enroth S, Uday S, Reinius B, et al. MEG3 long noncoding RNA regulates the TGF-beta pathway genes through formation of RNA-DNA triplex structures. Nat Commun. 2015;6:7743.

81. Long J, Badal SS, Ye Z, Wang Y, Ayanga BA, Galvan DL, et al. Long noncoding RNA Tug1 regulates mitochondrial bioenergetics in diabetic nephropathy. J Clin Invest. 2016;126(11):4205-18.

82. Chedin F. Nascent connections: R-loops and chromatin patterning. Trends Genet. 2016;32(12):828-38

83. Cloutier SC, Wang S, Ma WK, Al Husini N, Dhoondia Z, Ansari A, et al. Regulated formation of IncRNA-DNA hybrids enables faster transcriptional induction and environmental adaptation. Mol Cell. 2016;61(3):393-404.

84. Postepska-lgielska A, Giwojna A, Gasri-Plotnitsky L, Schmitt N, Dold A, Ginsberg D, et al. LnCRNA Khps1 regulates expression of the protooncogene SPHK1 via triplex-mediated changes in chromatin structure. Mol Cell. 2015;60(4):626-36

85. Ning $X$, Shi Z, Liu X, Zhang A, Han L, Jiang K, et al. DNMT1 and EZH2 mediated methylation silences the microRNA-200b/a/429 gene and promotes tumor progression. Cancer Lett. 2015;359(2):198-205.

86. Tsai CL, Liu WL, Hsu FM, Yang PS, Yen RF, Tzen KY, et al. Targeting histone deacetylase 4/ubiquitin-conjugating enzyme 9 impairs DNA repair for radiosensitization of hepatocellular carcinoma cells in mice. Hepatology. 2017:67:586-99.

87. Gai X, Tu K, Li C, Lu Z, Roberts LR, Zheng X. Histone acetyltransferase PCAF accelerates apoptosis by repressing a GLI1/BCL2/BAX axis in hepatocellular carcinoma. Cell Death Dis. 2015:6:e1712.

88. Mudbhary R, Hoshida Y, Chernyavskaya Y, Jacob V, Villanueva A, Fiel Ml, et al. UHRF1 overexpression drives DNA hypomethylation and hepatocellular carcinoma. Cancer Cell. 2014;25(2):196-209.

89. Taniue K, Kurimoto A, Sugimasa H, Nasu E, Takeda Y, Iwasaki K, et al. Long noncoding RNA UPAT promotes colon tumorigenesis by inhibiting degradation of UHRF1. Proc Natl Acad Sci U S A. 2016;113(5):1273-8.

90. Fu WM, Zhu X, Wang WM, Lu YF, Hu BG, Wang H, et al. Hotair mediates hepatocarcinogenesis through suppressing miRNA-218 expression and activating P14 and P16 signaling. J Hepatol. 2015;63(4):886-95.

91. Hu JJ, Song W, Zhang SD, Shen XH, Qiu XM, Wu HZ, et al. HBX-upregulated IncRNA UCA1 promotes cell growth and tumorigenesis by recruiting EZH2 and repressing p27Kip1/CDK2 signaling. Sci Rep. 2016;6:23521.

92. Peng Y, Croce CM. The role of MicroRNAs in human cancer. Signal Transduct Target Ther. 2016;1:15004.

93. Kretz M, Siprashvili Z, Chu C, Webster DE, Zehnder A, Qu K, et al. Control of somatic tissue differentiation by the long non-coding RNA TINCR. Nature. 2013:493(7431):231-5.

94. Engreitz JM, Sirokman K, McDonel P, Shishkin AA, Surka C, Russell P, et al. RNA-RNA interactions enable specific targeting of noncoding RNAs to nascent pre-mRNAs and chromatin sites. Cell. 2014;159(1):188-99.

95. Kallen AN, Zhou XB, Xu J, Qiao C, Ma J, Yan L, et al. The imprinted H19 IncRNA antagonizes let-7 microRNAs. Mol Cell. 2013;52(1):101-12.

96. Imig J, Brunschweiger A, Brummer A, Guennewig B, Mittal N, Kishore S, et al. miR-CLIP capture of a miRNA targetome uncovers a lincRNA H19-miR106a interaction. Nat Chem Biol. 2015;11(2):107-14.

97. Zheng J, Huang X, Tan W, Yu D, Du Z, Chang J, et al. Pancreatic cancer risk variant in LINC00673 creates a miR-1231 binding site and interferes with PTPN11 degradation. Nat Genet. 2016;48(7):747-57.

98. Kitagawa N, Ojima H, Shirakihara T, Shimizu H, Kokubu A, Urushidate T, et al. Downregulation of the microRNA biogenesis components and its 
association with poor prognosis in hepatocellular carcinoma. Cancer Sci. 2013;104(5):543-51.

99. Sun HL, Cui R, Zhou J, Teng KY, Hsiao YH, Nakanishi K, et al. ERK activation globally downregulates miRNAs through phosphorylating exportin-5. Cancer Cell. 2016;30(5):723-36.

100. Li J, Pu W, Sun HL, Zhou JK, Fan X, Zheng Y, et al. Pin1 impairs microRNA biogenesis by mediating conformation change of XPO5 in hepatocellular carcinoma. Cell Death Differ. 2018;25:1612-24.

101. Liu F, Yuan JH, Huang JF, Yang F, Wang TT, Ma JZ, et al. Long noncoding RNA FTX inhibits hepatocellular carcinoma proliferation and metastasis by binding MCM2 and miR-374a. Oncogene. 2016;35(41):5422-34.

102. Yan X, Zhang D, Wu W, Wu S, Qian J, Hao Y, et al. Mesenchymal stem cells promote hepatocarcinogenesis via IncRNA-MUF interaction with ANXA2 and miR-34a. Cancer Res. 2017;77(23):6704-16.

103. Qu L, Ding J, Chen C, Wu ZJ, Liu B, Gao Y, et al. Exosome-transmitted IncARSR promotes sunitinib resistance in renal cancer by acting as a competing endogenous RNA. Cancer Cell. 2016;29(5):653-68.

104. Hu X, Feng Y, Zhang D, Zhao SD, Hu Z, Greshock J, et al. A functional genomic approach identifies FAL1 as an oncogenic long noncoding RNA that associates with BMI1 and represses p21 expression in cancer. Cancer Cell. 2014;26(3):344-57.

105. Gou Q, Gao L, Nie X, Pu W, Zhu J, Wang Y, et al. Long noncoding RNA AB074169 inhibits cell proliferation via modulation of KHSRP-mediated CDKN1a expression in papillary thyroid carcinoma. Cancer Res. 2018;78(15): 4163-74.

106. Yan C, Chen J, Chen N. Long noncoding RNA MALAT1 promotes hepatic steatosis and insulin resistance by increasing nuclear SREBP-1c protein stability. Sci Rep. 2016;6:22640.

107. Tsai MC, Manor O, Wan Y, Mosammaparast N, Wang JK, Lan F, et al. Long noncoding RNA as modular scaffold of histone modification complexes. Science. 2010;329(5992):689-93.

108. Ye B, Liu B, Yang L, Zhu X, Zhang D, Wu W, et al. LncKdm2b controls selfrenewal of embryonic stem cells via activating expression of transcription factor Zbtb3. EMBO J. 2018;37(8):e97174.

109. Han P, Li W, Lin CH, Yang J, Shang C, Nuernberg ST, et al. A long noncoding RNA protects the heart from pathological hypertrophy. Nature. 2014:514(7520):102-6.

110. Lee S, Kopp F, Chang TC, Sataluri A, Chen B, Sivakumar S, et al. Noncoding RNA NORAD regulates genomic stability by sequestering PUMILIO proteins. Cell. 2016;164(1-2):69-80

111. Qin G, Tu X, Li H, Cao P, Chen X, Song J, et al. Long noncoding RNA p53stabilizing and activating RNA promotes p53 signaling by inhibiting heterogeneous nuclear ribonucleoprotein $\mathrm{k}$ deSUMOylation and suppresses hepatocellular carcinoma. Hepatology. 2020;71(1):112-29.

112. Zhang H, Xing Z, Mani SK, Bancel B, Durantel D, Zoulim F, et al. RNA helicase DEAD box protein 5 regulates Polycomb repressive complex 2/Hox transcript antisense intergenic RNA function in hepatitis B virus infection and hepatocarcinogenesis. Hepatology. 2016;64(4):1033-48.

113. Eddy SR. Computational analysis of conserved RNA secondary structure in transcriptomes and genomes. Annu Rev Biophys. 2014;43:433-56.

114. Rohrig H, Schmidt J, Miklashevichs E, Schell J, John M. Soybean ENOD40 encodes two peptides that bind to sucrose synthase. Proc Natl Acad Sci U S A. 2002;99(4):1915-20.

115. Rohrig H, John M, Schmidt J. Modification of soybean sucrose synthase by S-thiolation with ENOD40 peptide a. Biochem Biophys Res Commun. 2004; 325(3):864-70.

116. Ingolia NT, Brar GA, Stern-Ginossar N, Harris MS, Talhouarne GJ, Jackson SE, et al. Ribosome profiling reveals pervasive translation outside of annotated protein-coding genes. Cell Rep. 2014;8(5):1365-79.

117. Aspden JL, Eyre-Walker YC, Phillips RJ, Amin U, Mumtaz MA, Brocard M, et al. Extensive translation of small Open Reading Frames revealed by PolyRibo-Seq. Elife. 2014;3:e03528.

118. Ji Z, Song R, Regev A, Struhl K. Many IncRNAs, 5'UTRs, and pseudogenes are translated and some are likely to express functional proteins. Elife. 2015;4: e08890

119. Slavoff SA, Mitchell AJ, Schwaid AG, Cabili MN, Ma J, Levin JZ, et al. Peptidomic discovery of short open reading frame-encoded peptides in human cells. Nat Chem Biol. 2013;9(1):59-64.

120. Xu W, Deng B, Lin P, Liu C, Li B, Huang Q, et al. Ribosome profiling analysis identified a KRAS-interacting microprotein that represses oncogenic signaling in hepatocellular carcinoma cells. Sci China Life Sci. 2019. https:// doi.org/10.1007/s11427-019-9580-5.
121. Hanahan D, Weinberg RA. Hallmarks of cancer: the next generation. Cell. 2011;144(5):646-74.

122. Fan Y, Arechederra M, Richelme S, Daian F, Novello C, Calderaro J, et al. A phosphokinome-based screen uncovers new drug synergies for cancer driven by liver-specific gain of nononcogenic receptor tyrosine kinases. Hepatology. 2017;66(5):1644-61.

123. Ungerleider N, Han C, Zhang J, Yao L, Wu T. TGFbeta signaling confers sorafenib resistance via induction of multiple RTKs in hepatocellular carcinoma cells. Mol Carcinog. 2017;56(4):1302-11.

124. Wu SY, Lan SH, Wu SR, Chiu YC, Lin XZ, Su IJ, et al. Hepatocellular carcinoma-related cyclin D1 is selectively regulated by autophagy degradation system. Hepatology. 2018;68(1):141-54.

125. Wan J, Liu H, Yang L, Ma L, Liu J, Ming L. JMJD6 promotes hepatocellular carcinoma carcinogenesis by targeting CDK4. Int J Cancer. 2019;144(10):2489-500

126. Wang YL, Liu JY, Yang JE, Yu XM, Chen ZL, Chen YJ, et al. Lnc-UCID promotes $\mathrm{G} 1 / \mathrm{S}$ transition and hepatoma growth by preventing DHX9mediated CDK6 down-regulation. Hepatology. 2019;70(1):259-75.

127. Wang X, Zhang W, Tang J, Huang R, Li J, XU D, et al. LINC01225 promotes occurrence and metastasis of hepatocellular carcinoma in an epidermal growth factor receptor-dependent pathway. Cell Death Dis. 2016;7:e2130.

128. Keniry A, Oxley D, Monnier P, Kyba M, Dandolo L, Smits G, et al. The H19 lincRNA is a developmental reservoir of miR-675 that suppresses growth and Igf1r. Nat Cell Biol. 2012;14(7):659-65.

129. Latos PA, Pauler FM, Koerner MV, Senergin HB, Hudson QJ, Stocsits RR, et al. Airn transcriptional overlap, but not its IncRNA products, induces imprinted Igf2r silencing. Science. 2012;338(6113):1469-72.

130. Tang J, Zhuo H, Zhang $X$, Jiang R, Ji J, Deng L, et al. A novel biomarker Linc00974 interacting with KRT19 promotes proliferation and metastasis in hepatocellular carcinoma. Cell Death Dis. 2014;5:e1549.

131. Yang F, Zhang L, Huo XS, Yuan JH, Xu D, Yuan SX, et al. Long noncoding RNA high expression in hepatocellular carcinoma facilitates tumor growth through enhancer of zeste homolog 2 in humans. Hepatology. 2011;54(5):1679-89.

132. Rohrig F, Schulze A. The multifaceted roles of fatty acid synthesis in cancer. Nat Rev Cancer. 2016;16(11):732-49.

133. DeWaal D, Nogueira V, Terry AR, Patra KC, Jeon SM, Guzman G, et al. Hexokinase-2 depletion inhibits glycolysis and induces oxidative phosphorylation in hepatocellular carcinoma and sensitizes to metformin. Nat Commun. 2018:9(1):446.

134. Zheng L, Yang W, Wu F, Wang C, Yu L, Tang L, et al. Prognostic significance of AMPK activation and therapeutic effects of metformin in hepatocellular carcinoma. Clin Cancer Res. 2013;19(19):5372-80.

135. Liu C, Yang Z, Wu J, Zhang L, Lee S, Shin DJ, et al. Long noncoding RNA H19 interacts with polypyrimidine tract-binding protein 1 to reprogram hepatic lipid homeostasis. Hepatology. 2018;67(5):1768-83.

136. Sainz B Jr, Heeschen C. Standing out from the crowd: cancer stem cells in hepatocellular carcinoma. Cancer Cell. 2013;23(4):431-3.

137. Liu S, Li N, Yu X, Xiao X, Cheng K, Hu J, et al. Expression of intercellular adhesion molecule 1 by hepatocellular carcinoma stem cells and circulating tumor cells. Gastroenterology. 2013;144(5):1031-41 e10.

138. Yang W, Yan HX, Chen L, Liu Q, He YQ, Yu LX, et al. Wnt/beta-catenin signaling contributes to activation of normal and tumorigenic liver progenitor cells. Cancer Res. 2008;68(11):4287-95.

139. Chai S, Ng KY, Tong M, Lau EY, Lee TK, Chan KW, et al. Octamer 4/ microRNA-1246 signaling axis drives Wnt/beta-catenin activation in liver cancer stem cells. Hepatology. 2016;64(6):2062-76.

140. Lee TK, Castilho A, Cheung VC, Tang KH, Ma S, Ng IO. CD24(+) liver tumorinitiating cells drive self-renewal and tumor initiation through STAT3mediated NANOG regulation. Cell Stem Cell. 2011;9(1):50-63.

141. Cai $W Y$, Lin $L Y$, Hao H, Zhang SM, Ma F, Hong XX, et al. Yes-associated protein/TEA domain family member and hepatocyte nuclear factor 4-alpha (HNF4alpha) repress reciprocally to regulate hepatocarcinogenesis in rats and mice. Hepatology. 2017;65(4):1206-21.

142. Wang Y, He L, Du Y, Zhu P, Huang G, Luo J, et al. The long noncoding RNA IncTCF7 promotes self-renewal of human liver cancer stem cells through activation of Wnt signaling. Cell Stem Cell. 2015;16(4):413-25.

143. Chen ZZ, Huang L, Wu YH, Zhai WJ, Zhu PP, Gao YF. LncSox4 promotes the self-renewal of liver tumour-initiating cells through Stat3-mediated Sox4 expression. Nat Commun. 2016;7:12598.

144. Zhu P, Wang Y, Wu J, Huang G, Liu B, Ye B, et al. LncBRM initiates YAP1 signalling activation to drive self-renewal of liver cancer stem cells. Nat Commun. 2016;7:13608. 
145. Xiao S, Chang RM, Yang MY, Lei X, Liu X, Gao WB, et al. Actin-like 6A predicts poor prognosis of hepatocellular carcinoma and promotes metastasis and epithelial-mesenchymal transition. Hepatology. 2016;63(4):1256-71.

146. Yan $Q$, Jiang L, Liu M, Yu D, Zhang Y, Li Y, et al. ANGPTL1 interacts with integrin alpha1beta1 to suppress HCC angiogenesis and metastasis by inhibiting JAK2/STAT3 signaling. Cancer Res. 2017;77(21):5831-45.

147. Li T, Xie J, Shen C, Cheng D, Shi Y, Wu Z, et al. Upregulation of long noncoding RNA ZEB1-AS1 promotes tumor metastasis and predicts poor prognosis in hepatocellular carcinoma. Oncogene. 2016;35(12):1575-84.

148. Wang H, Liang L, Dong Q, Huan L, He J, Li B, et al. Long noncoding RNA miR503HG, a prognostic indicator, inhibits tumor metastasis by regulating the HNRNPA2B1/NF-kappaB pathway in hepatocellular carcinoma. Theranostics. 2018;8(10):2814-29.

149. Liang WC, Ren JL, Wong CW, Chan SO, Waye MM, Fu WM, et al. LnCRNANEF antagonized epithelial to mesenchymal transition and cancer metastasis via cis-regulating FOXA2 and inactivating Wnt/beta-catenin signaling. Oncogene. 2018;37(11):1445-56.

150. Zhang J, Li Z, Liu L, Wang Q, Li S, Chen D, et al. Long noncoding RNA TSLNC8 is a tumor suppressor that inactivates the interleukin-6/STAT3 signaling pathway. Hepatology. 2018;67(1):171-87.

151. Wu CY, Hsu YC, Ho HJ, Chen YJ, Lee TY, Lin JT. Association between ultrasonography screening and mortality in patients with hepatocellular carcinoma: a nationwide cohort study. Gut. 2016;65(4):693-701.

152. Tzartzeva K, Obi J, Rich NE, Parikh ND, Marrero JA, Yopp A, et al. Surveillance imaging and alpha fetoprotein for early detection of hepatocellular carcinoma in patients with cirrhosis: a meta-analysis. Gastroenterology. 2018; 154(6):1706-18 e1.

153. Chang TS, Wu YC, Tung SY, Wei KL, Hsieh YY, Huang HC, et al. Alphafetoprotein measurement benefits hepatocellular carcinoma surveillance in patients with cirrhosis. Am J Gastroenterol. 2015;110(6):836-44 quiz 45.

154. Di Bisceglie AM, Sterling RK, Chung RT, Everhart JE, Dienstag JL, Bonkovsky $\mathrm{HL}$, et al. Serum alpha-fetoprotein levels in patients with advanced hepatitis C: results from the HALT-C trial. J Hepatol. 2005;43(3):434-41.

155. Moon AM, Weiss NS, Beste LA, Su F, Ho SB, Jin GY, et al. No association between screening for hepatocellular carcinoma and reduced cancerrelated mortality in patients with cirrhosis. Gastroenterology. 2018;155:11281139.e6.

156. Yu J, Han J, Zhang J, Li G, Liu H, Cui X, et al. The long noncoding RNAs PVT1 and uc002mbe.2 in sera provide a new supplementary method for hepatocellular carcinoma diagnosis. Medicine (Baltimore). 2016;95(31):e4436.

157. Klingenberg M, Matsuda A, Diederichs S, Patel T. Non-coding RNA in hepatocellular carcinoma: mechanisms, biomarkers and therapeutic targets. J Hepatol. 2017:67(3):603-18

158. Huarte M. The emerging role of IncRNAs in cancer. Nat Med. 2015;21(11): 1253-61.

159. Ma P, Pan Y, Li W, Sun C, Liu J, Xu T, et al. Extracellular vesicles-mediated noncoding RNAs transfer in cancer. J Hematol Oncol. 2017;10(1):57.

160. Merchant ML, Rood IM, Deegens JKJ, Klein JB. Isolation and characterization of urinary extracellular vesicles: implications for biomarker discovery. Nat Rev Nephrol. 2017;13(12):731-49.

161. Llovet JM, Montal R, Sia D, Finn RS. Molecular therapies and precision medicine for hepatocellular carcinoma. Nat Rev Clin Oncol. 2018;15(10):599616.

162. Fu X, Zhu X, Qin F, Zhang Y, Lin J, Ding Y, et al. Linc00210 drives Wnt/betacatenin signaling activation and liver tumor progression through CTNNBIP1dependent manner. Mol Cancer. 2018;17(1):73.

163. Matsui M, Corey DR. Non-coding RNAs as drug targets. Nat Rev Drug Discov. 2017;16(3):167-79.

164. Lennox KA, Behlke MA. Cellular localization of long non-coding RNAs affects silencing by RNAi more than by antisense oligonucleotides. Nucleic Acids Res. 2016;44(2):863-77

165. Wheeler TM, Leger AJ, Pandey SK, MacLeod AR, Nakamori M, Cheng SH, et al. Targeting nuclear RNA for in vivo correction of myotonic dystrophy. Nature. 2012:488(7409):111-5.

166. Javanbakht H, Mueller H, Walther J, Zhou X, Lopez A, Pattupara T, et al. Liver-targeted anti-HBV single-stranded oligonucleotides with locked nucleic acid potently reduce HBV gene expression in vivo. Mol Ther Nucleic Acids. 2018;11:441-54.

167. Thi EP, Dhillon AP, Ardzinski A, Bidirici-Ertekin L, Cobarrubias KD, Cuconati A, et al. ARB-1740, a RNA interference therapeutic for chronic hepatitis B infection. ACS Infect Dis. 2019;5(5):725-37.
168. Necsulea A, Soumillon M, Warnefors M, Liechti A, Daish T, Zeller U, et al. The evolution of IncRNA repertoires and expression patterns in tetrapods. Nature. 2014;505(7485):635-40.

169. Juan V, Crain C, Wilson C. Evidence for evolutionarily conserved secondary structure in the H19 tumor suppressor RNA. Nucleic Acids Res. 2000;28(5): 1221-7.

170. Pegueroles C, Gabaldon T. Secondary structure impacts patterns of selection in human IncRNAs. BMC Biol. 2016;14:60.

171. Patil DP, Chen CK, Pickering BF, Chow A, Jackson C, Guttman M, et al. M(6) a RNA methylation promotes XIST-mediated transcriptional repression. Nature. 2016:537(7620):369-73.

172. Zuo X, Chen Z, Gao W, Zhang Y, Wang J, Wang J, et al. M6A-mediated upregulation of LINC00958 increases lipogenesis and acts as a nanotherapeutic target in hepatocellular carcinoma. J Hematol Oncol. 2020; 13(1):5.

173. Liu N, Dai Q, Zheng G, He C, Parisien M, Pan T. N(6)-methyladenosinedependent RNA structural switches regulate RNA-protein interactions. Nature. 2015;518(7540):560-4

174. Feyder M, Goff LA. Investigating long noncoding RNAs using animal models. J Clin Invest. 2016;126(8):2783-91.

175. Li L, Chang HY. Physiological roles of long noncoding RNAs: insight from knockout mice. Trends Cell Biol. 2014:24(10):594-602.

176. Hosono Y, Niknafs YS, Prensner JR, lyer MK, Dhanasekaran SM, Mehra R, et al. Oncogenic role of THOR, a conserved cancer/testis long non-coding RNA. Cell. 2017;171(7):1559-72 e20.

177. Sauvageau M, Goff LA, Lodato S, Bonev B, Groff AF, Gerhardinger C, et al. Multiple knockout mouse models reveal lincRNAs are required for life and brain development. Elife. 2013;2:e01749.

\section{Publisher's Note}

Springer Nature remains neutral with regard to jurisdictional claims in published maps and institutional affiliations.

Ready to submit your research? Choose BMC and benefit from:

- fast, convenient online submission

- thorough peer review by experienced researchers in your field

- rapid publication on acceptance

- support for research data, including large and complex data types

- gold Open Access which fosters wider collaboration and increased citations

- maximum visibility for your research: over $100 \mathrm{M}$ website views per year

At BMC, research is always in progress.

Learn more biomedcentral.com/submission 